\title{
Maturation of human oocytes in vitro and their developmental competence
}

\author{
Alan Trounson, Cleola Anderiesz and Gayle Jones \\ Centre for Early Human Development, Monash Institute of Reproduction and Development, \\ Monash University, Monash Medical Centre, Clayton, Victoria 3168, Australia
}

\begin{abstract}
Complete maturation of oocytes is essential for the developmental competence of embryos. Any interventions in the growth phase of the oocyte and the follicle in the ovary will affect oocyte maturation, fertilization and subsequent embryo development. Oocyte size is associated with maturation and embryo development in most species examined and this may indicate that a certain size is necessary to initiate the molecular cascade of normal nuclear and cytoplasmic maturation. The minimum size of follicle required for developmental competence in humans is $5-7 \mathrm{~mm}$ in diameter. Maturation in vitro can be accomplished in humans, but is associated with a loss of developmental competence unless the oocyte is near completion of its preovulatory growth phase. This loss of developmental competence is associated with the absence of specific proteins in oocytes cultured to metaphase II in vitro. The composition of culture medium used successfully for maturation of human oocytes is surprisingly similar to that originally developed for maturation of oocytes in follicle culture in vitro. The presence of follicle support cells in culture is necessary for the gonadotrophin-mediated response required to mature oocytes in vitro. Gonadotrophin concentration and the sequence of FSH and FSH-LH exposure may be important for human oocytes, particularly those not exposed to the gonadotrophin surge in vivo. More research is needed to describe the molecular and cellular events, the presence of checkpoints and the role of gene expression, translation and protein uptake on completing oocyte maturation in vitro and in vivo. In the meantime, there are very clear applications for maturing oocytes in human reproductive medicine and the success rates achieved in some of these special applications are clinically valuable.
\end{abstract}

\begin{abstract}
Oocyte maturation remains an enigmatic process that is generally understood to span the time from when messages initiate germinal vesicle breakdown (GVBD) to completion of the nuclear changes resulting in expulsion of the first polar body. The process of maturation encompasses a complex series of molecular and structural events, culminating in the arrest of the oocyte chromosomes on the metaphase II plate in anticipation of sperm penetration and activation for fertilization. There is no agreed assay for the completion of oocyte maturation, other than the full developmental competence of the fertilized oocyte to fully formed live born offspring. Completion of the nuclear changes to produce a metaphase II oocyte does not identify developmental competence and does not reflect the molecular and structural maturity of an oocyte, which is sometimes termed cytoplasmic maturation. It is well
\end{abstract}

Email: christine.hi@med.monash.edu.au known that oocytes will progress spontaneously through the nuclear changes characteristic of oocyte maturation when they are liberated from the antral follicle and cultured in vitro (Pincus and Enzmann, 1935; Edwards, 1965). GVBD may be observed in oocytes in advanced stages of follicular atresia when follicular support cells have died. Hence progression of meiosis to metaphase I or II could be representative of either oocyte degeneration or oocyte maturation. Studies in the mid-1970s by Thibault et al. (1975) and Moor and Trounson (1977) showed that, in species such as rabbits and sheep that have an obligatory phase of protein synthesis during maturation, a complete follicle was necessary to mature oocytes fully. By maintaining the primary elements of follicular culture and retaining granulosa cell viability and function, Staigmiller and Moor (1984) were able to retain maturation and developmental competence of sheep oocyte-cumulus cell complexes in culture when they were removed from the follicular environment. 


\section{Follicular size, oocyte maturation and developmental competence}

Follicular development in monovular species is characterized by recruitment of primordial follicles for an extended period of follicular growth, selection of a dominant follicle destined for ovulation, and atresia of the remaining cohort. Follicle development is a continuum that begins at birth and continues to the end of reproductive life. The human oocyte grows from a diameter of $35 \mu \mathrm{m}$ to a final diameter of $120 \mu \mathrm{m}$ over several months (Gosden and Bownes, 1995; Gougeon, 1996). During this period the oocyte synthesizes and stores mRNA and proteins essential for the completion of maturation and for the subsequent acquisition of embryo developmental competence and ongoing viability. In humans, during the late luteal phase of the preceding menstrual cycle, the largest non-atretic follicles range in size between 2 and $5 \mathrm{~mm}$ in diameter (Gougeon and Lefevre, 1983; McNatty et al., 1983). In the early follicular phase, the largest follicle ranges in size from 5.5 to $8.2 \mathrm{~mm}$ and this is usually the follicle that achieves dominance and continues growth to ovulation (Gougeon and Lefevre, 1983). The preovulatory follicle develops to a diameter of $18.8 \pm 0.5 \mathrm{~mm}$ by the late follicular phase (Gougeon and Lefevre, 1983) and expands rapidly after the mid-cycle LH surge to a diameter of $\geqslant 25 \mathrm{~mm}$.

Antrum formation in the rodent follicle occurs at about the time oocytes complete their growth and the oocyte has acquired the capacity to resume meiosis (Eppig and Schroeder, 1989). In mice, a polyovular species, oocytes from early antral follicles are competent to resume the first meiotic division (Sorensen and Wassarman, 1976) and when isolated from the follicle undergo spontaneous resumption of meiosis. However, competence of oocytes to complete maturation beyond the first meiotic division is not conferred in mice until the follicle is much larger (Eppig and Schroeder, 1989). Developmental competence, as shown by the ability to undergo fertilization and develop to the blastocyst stage, is dependent on both the size of the follicle and the size of the oocyte (Eppig et al., 1992).

The capacity for meiotic competence in rabbits (Bae and Foote, 1975), cows (Sato et al., 1977), pigs (Tsafiri and Channing, 1975), sheep (Moor and Trounson, 1977), goats (Martino et al., 1994), horses (Goudet et al., 1997) and rhesus monkeys (Schramm et al., 1993) increases with follicle size and is not strictly correlated with antrum formation or maximum oocyte diameter, which occurs later. Marmoset monkeys are similar to mice in that meiotic competence occurs concomitantly with antrum formation (Adachi et al., 1982; Gilchrist et al., 1995). However, follicular antrum formation occurs at different stages of folliculogenesis in different species. Antrum formation occurs in human and bovine follicles at $2 \%$ of the final ovulatory diameter (Motlik and Fulka, 1986; Greenwald and Terranova, 1988). In rhesus monkeys, an antrum appears at 3\% (Greenwald and Terranova, 1988), in pigs at $4.5 \%$
(Motlik and Fulka, 1986) and in marmoset monkeys at $15 \%$ of final ovulatory diameter (Gilchrist et al., 1995). Consequently it is also more appropriate to consider meiotic competence in relation to follicular diameter as a proportion of ovulatory size. Marmoset monkey oocytes from follicles at $2 \%$ of final ovulatory diameter are meiotically incompetent (Gilchrist et al., 1995).

In all non-rodent species studied, the ability of oocytes to resume meiosis is acquired when the diameter of the follicle is about $9-13 \%$ of the ovulatory diameter, a stage by which oocyte growth is completed (Gilchrist et al., 1995). In oocytes, the ability to complete maturation to metaphase II and developmental competence is acquired progressively with increasing follicular diameter. Goat oocytes from follicles $>5 \mathrm{~mm}$ in diameter undergo fertilization and develop to blastocysts at rates comparable to ovulated oocytes (Crozet et al., 1995). Cow oocytes from follicles $>6 \mathrm{~mm}$ have about twice the developmental potential of oocytes from 2-6 mm follicles (Tan and Lu, 1990; McCaffrey et al., 1992; Lonergan et al., 1994). Cow oocytes from follicles $<3 \mathrm{~mm}$ not only show a significantly lower rate of maturation and fertilization but also fail to cleave beyond the 8- to 16-cell stage of development (Pavlok et al., 1992; Blondin and Sirard, 1995). Follicle diameter and oocyte diameter are significantly correlated in the cow for follicles in the range of $<1 \mathrm{~mm}$ to $\geqslant 4 \mathrm{~mm}$, and the proportion of oocytes completing maturation to metaphase II in vitro is associated with increasing oocyte diameter, at least up to $110 \mu \mathrm{m}$ in diameter. Cow oocytes $<110 \mu \mathrm{m}$ show a significant increase in the incorporation of tritiated uridine compared with larger oocytes, indicating that the smaller oocytes are in the growth phase and still actively synthesizing RNA that is essential to maturation and later development (Fair et al., 1995). In cows, oocytes appear to acquire full meiotic competence at a diameter of $115 \mu \mathrm{m}$ and attain the competence for preimplantation embryonic development to expanded and hatching blastocysts at a diameter of $120 \mu \mathrm{m}$ (Otoi et al., 1997).

Human and macaque oocytes resume spontaneous meiosis in vitro at a very low rate compared with other species (Edwards, 1965). The explanation for this observation could be that meiotic competence occurs relatively late in the growth phase or that maturation requires both stimulation and removal of inhibition (Lefevre et al., 1987). The human oocyte has a size-dependent ability to resume meiosis and complete maturation in vitro and this increases significantly as the oocyte increases in diameter from 90 to $120 \mu \mathrm{m}$ (Durinzi et al., 1995). Furthermore, this size-dependent ability for meiotic competence may also depend on the size of the follicle and the stage of the menstrual cycle. Oocytes retrieved from the follicular phase of the menstrual cycle from follicles of 9-15 mm in diameter complete meiotic maturation to metaphase II at a higher rate than oocytes from follicles of 3-4 $\mathrm{mm}$ in diameter (Tsuji et al., 1985; Whitacre et al., 1998). Wynn et al. (1998) reported that $5 \mathrm{~mm}$ was the minimum follicle 
diameter from which oocytes would mature in vitro. Oocytes retrieved from follicles in the luteal phase of the menstrual cycle completed maturation at the same rate irrespective of follicle size (Tsuji et al., 1985).

Many studies have been undertaken to determine the effect of follicle size on the maturational status and subsequent fertilization, development and competence of the human oocytes from gonadotrophin-stimulated ovulatory cycles. The incidence of mature oocytes recovered after superovulation with human menopausal gonadotrophin (hMG) and human chorionic gonadotrophin (hCG) increases with increasing follicular size (Simonetti et al., 1985). The proportion of mature oocytes from follicles $\geqslant 15 \mathrm{~mm}$ in diameter remained constant. In follicles $<15 \mathrm{~mm}$ in diameter there was a significant reduction in mature oocytes; only $30 \%$ of oocytes mature in follicles of $12-14 \mathrm{~mm}$ and $9 \%$ in follicles $<11 \mathrm{~mm}$ in diameter (Scott et al., 1989). There is widespread opinion that after gonadotrophin stimulation the fertilization rate is lower in oocytes obtained from follicles $<10 \mathrm{~mm}$ in diameter than in those obtained from larger follicles (Wittmaack et al., 1994; Dubey et al., 1995; Salha et al., 1998a). This low fertilization rate is probably due to the increase in immature oocytes recovered from smaller follicles. Fertilization has been reported to increase progressively with an increase in follicle diameter from $10 \mathrm{~mm}$ (Dubey et al., 1995), although others have reported that once a follicle has reached 10-12 mm in diameter the fertilization rate remains relatively constant with progressive follicle growth (Haines and Emes, 1991; Wittmaack et al., 1994; Salha et al., 1998a). Embryo cleavage rates were reported to be significantly decreased or not significantly different for oocytes obtained from follicles $<12 \mathrm{~mm}$ in diameter. Embryo quality (assessed on morphology of the blastomeres and degree of fragmentation), implantation, pregnancy and birth rates appear to be independent of follicle size in stimulated cycles (Wittmaack et al., 1994; Salha et al., 1998a).

In monovular species, one or two follicles become dominant in the final growth phase, leading to a marked increase in the ratio of oestrogen:androgen of the dominant follicle or follicles. The remaining cohort of antral follicles remain androgen dominated and ultimately undergo atresia. Prolonged exposure to androgens in sub-dominant follicles may have an adverse effect on oocyte viability and developmental competence (Anderiesz and Trounson, 1995). In humans, the dominant follicle can usually be recognized by ultrasonography when it has reached $10 \mathrm{~mm}$ in diameter (Fauser and van Heusden, 1997). In a large study of gonadotrophin-stimulated IVF cycles, Wittmaack et al. (1994) reported that the size of the leading follicle did not affect the fertilization and cleavage rates of cohort oocytes. In contrast, Russell (1998) reported a marked decrease in the rates of maturation, fertilization and transfer among cycles in which immature oocytes were retrieved when a dominant follicle of $\geqslant 14 \mathrm{~mm}$ was present at the time of retrieval.

Studies in this laboratory indicate that oocytes retrieved from follicles in an untreated natural cycle, or from a cycle in which clomiphene citrate is used for minimal ovarian stimulation, are capable of complete development to the blastocyst stage after administration of exogenous hCG (5000 iu) to induce maturation in vivo as early as day 8 of the menstrual cycle with a leading follicle diameter of $12 \mathrm{~mm}$ (Table 1). Mature oocytes were recovered by transvaginal aspiration $36 \mathrm{~h}$ after hCG administration. Development of embryos in the cohort follicles in these cycles appeared to be independent of the diameter of the leading follicle at the time of hCG injection (Table 2). Development to the blastocyst stage was observed from the smallest follicle $(6 \mathrm{~mm})$ retrieved in this study (Fig. 1). A live birth resulted from the transfer of a single blastocyst from a follicle measuring only $11 \mathrm{~mm}$ at the time of hCG injection when the leading follicle was $19 \mathrm{~mm}$ in diameter. Sixty-one per cent of all the oocytes retrieved and fertilized developed to the blastocyst stage, a number comparable to that observed in gonadotrophin-stimulated cycles (hMG or FSH and hCG treated) using identical culture conditions (Jones et al., 1998). In our studies, patients with regular menstrual cycles undergoing an in vitro maturation cycle have a leading follicle $>9 \mathrm{~mm}$ in diameter by days $8-13$ of the menstrual cycle in $79 \%$ of cases, but anovulatory or irregularly ovulating patients with polycystic ovarian disease syndrome (PCOS) rarely have a leading follicle $>9 \mathrm{~mm}$ in diameter at the time of immature oocyte recovery. These data indicate that the developmental competence of the in vitro matured oocyte must be compromised by some inherent but unidentified problem in the maturation process in vitro rather than being directly related to reduced follicle size, at least for follicles $>6 \mathrm{~mm}$ in diameter.

\section{Source of oocytes used for in vitro oocyte maturation}

Oocytes of farm animals can be obtained from abattoirs after slaughter of the animals. Ovaries are recovered from the animals and kept in warm PBS for transport to the laboratory. Oocytes are then aspirated from the antral follicles visible on the surface of the ovary or identified under the dissecting microscope from minced ovarian tissue. Cows in different phases of the ovulatory cycle (follicular and luteal) or even pregnant at the time they are killed do not show any marked difference in the maturational competence of oocytes. Maturation in vitro of cow oocytes recovered by transvaginal ultrasonography show comparable developmental competence to oocytes matured in the ovaries of animals and grown to blastocysts in the donor (Bousquet et al., 1999). In this large scale study, the donor cows were given 4 days of FSH treatment (total of $400 \mathrm{mg}$ $\mathrm{FSH}$ ) after removal of the dominant follicle and the oocytes were recovered $44-48 \mathrm{~h}$ after the end of $\mathrm{FSH}$ treatment. Oocyte developmental competence was not compromised by either maturation in vitro, IVF or embryo culture (Fig. 2). The medium used for maturation was tis- 
Table 1. Diameter of the leading dominant follicle on the day of human chorionic gonadotrophin (hCG) injection and its relationship to human embryo development

\begin{tabular}{|c|c|c|c|c|c|c|c|}
\hline \multirow{2}{*}{$\begin{array}{l}\text { Diameter of } \\
\text { leading } \\
\text { dominant } \\
\text { follicle }\end{array}$} & \multirow[b]{2}{*}{$\begin{array}{l}\text { Number of } \\
\text { cycles }\end{array}$} & \multirow{2}{*}{$\begin{array}{c}\text { Oocytes } \\
\text { recovered } \\
\text { from leading } \\
\text { dominant } \\
\text { follicle }\end{array}$} & \multirow{2}{*}{$\begin{array}{l}\text { Oocytes } \\
\text { fertilized } \\
\text { from } \\
\text { leading } \\
\text { dominant } \\
\text { follicle }\end{array}$} & \multicolumn{4}{|c|}{ Maximum stage of embryo development (\%) } \\
\hline & & & & $\begin{array}{l}\text { Cleavage } \\
\text { only }\end{array}$ & Morula & Blastocyst & $\begin{array}{c}\text { Expanded/hatched } \\
\text { blastocyst }\end{array}$ \\
\hline 10 & 1 & 1 & 0 & & & & \\
\hline 11 & 0 & 0 & & & & & \\
\hline 12 & 1 & 1 & 1 & & & 1 & \\
\hline 13 & 3 & 2 & 2 & 1 & & 1 & \\
\hline 14 & 3 & 2 & 1 & & & & 1 \\
\hline 15 & 9 & 6 & 4 & 2 & & & 2 \\
\hline 16 & 8 & 4 & 2 & & & & 2 \\
\hline 17 & 8 & 4 & 1 & & & 1 & \\
\hline 18 & 6 & 2 & 2 & 1 & 1 & & \\
\hline 19 & 8 & 6 & 5 & 1 & 2 & 1 & 1 \\
\hline 20 & 2 & 2 & 2 & 2 & & & \\
\hline 21 & 4 & 2 & 2 & 1 & 1 & & \\
\hline 22 & 3 & 3 & 1 & & 1 & & \\
\hline 26 & 1 & 1 & 1 & & 1 & & \\
\hline Total & 57 & 36 & 24 & $8(33 \%)$ & $6(25 \%)$ & $4(17 \%)$ & $6(25 \%)$ \\
\hline
\end{tabular}

Table 2. Influence of the diameter of the leading follicle on human embryo development in the cohort follicles

\begin{tabular}{|c|c|c|c|c|c|c|c|}
\hline \multirow{2}{*}{$\begin{array}{l}\text { Diameter } \\
\text { of leading } \\
\text { dominant } \\
\text { follicle }\end{array}$} & \multirow[b]{2}{*}{$\begin{array}{l}\text { Number of } \\
\text { cycles }\end{array}$} & \multirow{2}{*}{$\begin{array}{l}\text { Number } \\
\text { of oocytes } \\
\text { from cohort } \\
\text { follicles }\end{array}$} & \multirow{2}{*}{$\begin{array}{l}\text { Number of } \\
\text { zygotes } \\
\text { from cohort } \\
\text { follicles }\end{array}$} & \multicolumn{4}{|c|}{ Maximum stage of embryo development (\%) } \\
\hline & & & & $\begin{array}{l}\text { Cleavage } \\
\text { only }\end{array}$ & Morula & Blastocyst & $\begin{array}{c}\text { Expanded/hatched } \\
\text { blastocyst }\end{array}$ \\
\hline 10 & 1 & 0 & & & & & \\
\hline 11 & 0 & 0 & & & & & \\
\hline 12 & 1 & 0 & & & & & \\
\hline 13 & 3 & 2 & 1 & & 1 & & \\
\hline 14 & 3 & 4 & 2 & 1 & & 1 & \\
\hline 15 & 9 & 11 & 5 & 4 & 1 & & \\
\hline 16 & 8 & 8 & 5 & 1 & & 1 & 3 \\
\hline 17 & 8 & 14 & 12 & 3 & & 3 & 6 \\
\hline 18 & 6 & 8 & 4 & & 2 & & 2 \\
\hline 19 & 8 & 8 & 4 & 1 & 1 & 1 & 1 \\
\hline 20 & 2 & 1 & 1 & & & & 1 \\
\hline 21 & 4 & 7 & 5 & & & 1 & 4 \\
\hline 22 & 3 & 9 & 6 & 1 & 1 & 2 & 2 \\
\hline 26 & 1 & 2 & 1 & & 1 & & \\
\hline Total & 57 & 74 & 46 & $11(24 \%)$ & 7 (15\%) & $9(20 \%)$ & $19(41 \%)$ \\
\hline
\end{tabular}

sue culture medium 199 (TCM 199) with 10\% fetal bovine serum (FBS), $0.5 \mu \mathrm{g} \mathrm{FSH} \mathrm{ml}{ }^{-1}, 5 \mu \mathrm{g} \mathrm{LH} \mathrm{ml}{ }^{-1}$ and $1 \mu \mathrm{g}$ oestradiol $\mathrm{ml}^{-1}$, and is similar to that used by Moor and Trounson (1977) for the successful maturation of sheep oocytes in follicle culture. A detailed consideration of the gonadotrophin, steroid and growth factor benefits for bovine oocyte maturation (Bevers et al., 1997) indicates that the major benefits are from components that are already present in the TCM 199 medium described above. This finding indicates that the factors governing oocyte maturation in vitro are primarily intrinsic to the follicle, oocyte-cumulus mass or the oocyte itself. Surprisingly, only relatively minor changes in developmental competence of animal and human oocytes have been recorded in numerous studies on culture media and conditions for oocyte maturation. 


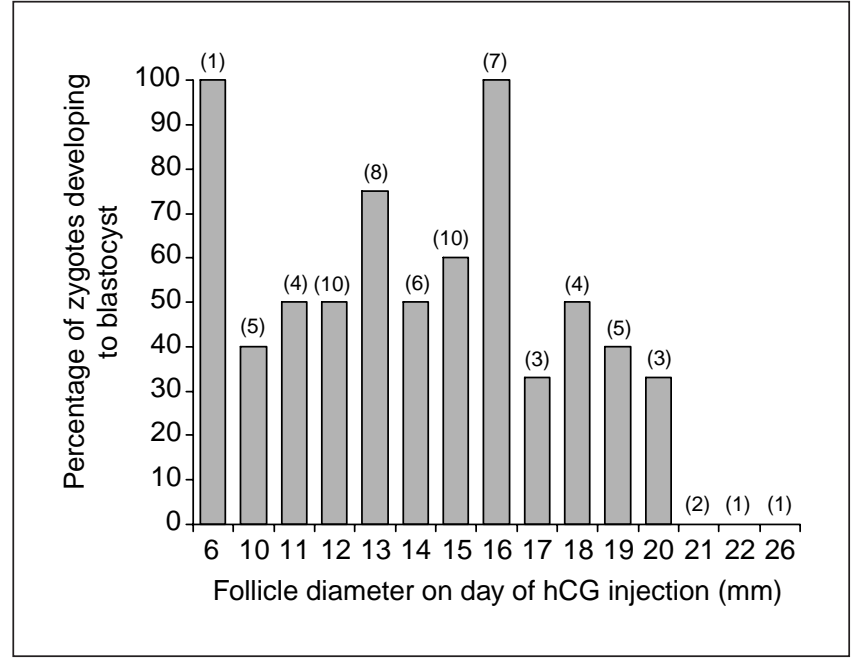

Fig. 1. Influence of the diameter of the follicle on the day of human chorionic gonadotrophin (hCG) injection on subsequent development to the blastocyst stage. The values in parentheses are number of embryos $(n)$.

\section{Immature oocytes from PCOS patients}

Methods were developed by Trounson et al. (1994) for the recovery of oocytes from the ovaries of patients with PCOS in which the dominance of a particular follicle fails to occur and the cohort of growing follicles accumulates in the cortex. Most of these follicles are about $5 \mathrm{~mm}$ in diameter (range 3-8 $\mathrm{mm}$ ) and remain under an androgendominated environment due to increased thecal cell secretion of androgens and a blockage of aromatization in the granulosa cell compartments (Almahbobi and Trounson, 1996). It is not uncommon for $\geqslant 20$ small to medium sized antral follicles to be present in each ovary of PCOS patients. When oocytes are recovered by transvaginal guided ultrasonography they can be readily identified and will undergo nuclear maturation in a number of different culture media, undergo fertilization after insemination or intracytoplasmic sperm injection (ICSI) and begin cleavage in culture (Trounson et al., 1994, 1996, 1998). Compared with oocytes recovered from regularly cyclic non-PCOS women, oocyte maturation, fertilization and embryo development in culture is significantly retarded (Barnes et al., 1996). However, babies have been born from the cleaving embryos and blastocysts produced as a result of in vitro oocyte maturation (Trounson et al., 1994; Barnes et al., 1995) although implantation rates are generally low (Trounson et al., 1998). Barnes et al. (1996) also suggested that oocytes from PCOS patients were at a disadvantage because of the abnormal endocrine environment and stasis of follicular growth. It is of interest to note that most of the follicles in these PCOS patients are not atretic (Almahbobi et al., 1996), nor does follicular atresia appear to reduce the developmental competence of human oocytes (Barnes et al., 1996). A marked improvement in viability of embryos produced from in vitro maturation of oocytes derived from

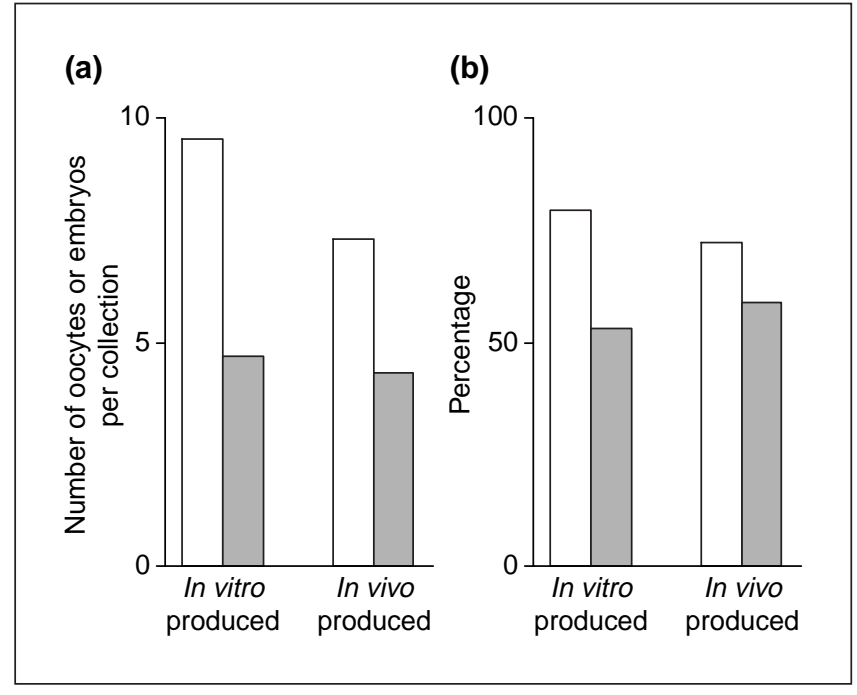

Fig. 2. Developmental competence of in vitro produced (matured, fertilized and cultured) bovine oocytes compared with that of oocytes produced in vivo. Data for 4145 in vitro matured oocytes and 1652 embryos recovered from superovulated donors (day 7 after oestrus). (a) Number of oocytes or embryos per collection ( $\square$ ); number of usable embryos ( $\square$ ). (b) Embryo cleavage (\%, $\square$ ); pregnancy at day $60(\%, \square)$. Data from Bousquet et al. (1999).

PCOS patients was reported by Cha and Chian (1998). They recovered 910 oocytes from 72 PCOS cases (12.6 oocytes per case) and of 832 oocytes cultured, 499 (60\%) matured to metaphase II. Eighty per cent of the metaphase II oocytes underwent fertilization and 306 embryos were transferred to 64 patients (4.7 embryos per patient) to yield 16 pregnancies (one twin pregnancy). The overall implantation rate was $5.6 \%$ per embryo transferred, but notably a mixture of pronuclear oocytes and early cleavage stage embryos was transferred in this study.

The media used to mature human oocytes by Cha and Chian (1998) was TCM 199 with 20\% FBS and contained $10 \mathrm{iu}$ equine chorionic gonadotrophin (eCG) $\mathrm{ml}^{-1}$ and 10 iu hCG $\mathrm{ml}^{-1}$. eCG has approximately 50:50 FSH and $\mathrm{LH}$ bioactivity. This medium is again very much like the original follicle culture medium of Moor and Trounson (1977) and, like the successful bovine oocyte maturation medium, contains a large quantity of FBS. FBS is considered crucial for bovine oocyte maturation and may also contain factors essential for human oocyte maturation (Barnes, 1999). A medium designed to meet the nutritional and maturational needs of human oocytes based on a detailed review of oocyte metabolism and developmental competence (human oocyte maturation (HOM) medium; Table 3) has been tested for maturation, fertilization and embryo development of oocytes recovered from PCOS patients without any apparent benefit for these parameters compared with a commonly used commercial amniocyte culture medium that contains bovine serum (Chang's medium; Trounson et al., 1998). There is a need to explore more extensively the role of culture medium and additives 
Table 3. Composition of human oocyte maturation (HOM) medium

\begin{tabular}{lc}
\hline Component & Concentration \\
\hline $\mathrm{NaCl}$ & $105 \mathrm{mmol} \mathrm{I}^{-1}$ \\
$\mathrm{KCl}$ & $5.5 \mathrm{mmol} \mathrm{I}^{-1}$ \\
$\mathrm{NaH}_{2} \mathrm{PO}_{4} \cdot 2 \mathrm{H}_{2} \mathrm{O}$ & $0.5 \mathrm{mmol} \mathrm{I}^{-1}$ \\
$\mathrm{CaCl}_{2} \cdot 2 \mathrm{H}_{2} \mathrm{O}$ & $1.8 \mathrm{mmol} \mathrm{I}^{-1}$ \\
$\mathrm{MgSO}_{4} \cdot 7 \mathrm{H}_{2} \mathrm{O}$ & $1.0 \mathrm{mmol} \mathrm{I}^{-1}$ \\
$\mathrm{NaHCO}$ & $25.0 \mathrm{mmol} \mathrm{I}^{-1}$ \\
Sodium lactate & $3.0 \mathrm{mmol} \mathrm{I}^{-1}$ \\
Sodium pyruvate & $0.3 \mathrm{mmol} \mathrm{I}^{-1}$ \\
Glucose & $5.5 \mathrm{mmol} \mathrm{I}^{-1}$ \\
Glutamine & $1.0 \mathrm{mmol} \mathrm{I}^{-1}$ \\
Taurine & $0.1 \mathrm{mmol} \mathrm{I}^{-1}$ \\
Cysteine & $0.1 \mathrm{mmol} \mathrm{I}^{-1}$ \\
Cysteamine & $0.5 \mathrm{mmol} \mathrm{I}^{-1}$ \\
Essential amino acids (EAA) & $1 \times$ \\
Non-essential amino acids (NEAA) & $2 \times$ \\
Penicillin & $0.06 \mathrm{~g} \mathrm{I}^{-1}$ \\
Streptomycin & $0.05 \mathrm{~g} \mathrm{I}^{-1}$ \\
EDTA & $0.1 \mathrm{mmol} \mathrm{I}^{-1}$ \\
Vitamins & $0.1 \times$ \\
Human serum albumin & $2 \mathrm{mg} \mathrm{ml}^{-1}$ \\
Recombinant FSH & $0.1 \mathrm{iu} \mathrm{ml}^{-1}$ \\
Recombinant LH & $0.5 \mathrm{iu} \mathrm{ml}^{-1}$ \\
Epidermal growth factor (EGF) & $10 \mathrm{ml}^{-1}$ \\
Insulin transferrin sodium selenite medium & \\
supplement (ITS) & \\
Oestradiol & \\
\hline & \\
\hline & \\
\hline
\end{tabular}

EAA: ICN (catalogue no. 1681149$) 50 \times$ solution; use $200 \mu \mathrm{l}$ per $10 \mathrm{ml}$ to give $1 \times$ concentration.

NEAA: ICN (catalogue no. 1681049) $100 \times$ solution; use $200 \mu \mathrm{l}$ per $10 \mathrm{ml}$ to give $2 \times$ concentration

Vitamins: ICN (catalogue no. 1601449) $100 \times$ solution; use $10 \mu \mathrm{l}$ per $10 \mathrm{ml}$ to give $0.1 \times$ concentration.

EGF: Sigma (catalogue no. E1264) $100 \mu \mathrm{g}$ per vial; prepare $100 \mu \mathrm{g}$ per $10 \mathrm{ml}$ stock solution in HOM salts $+0.3 \%\left(3 \mathrm{mg} \mathrm{ml}^{-1}\right) \mathrm{HSA}$. Add $10 \mu \mathrm{l}$ per $10 \mathrm{ml}$ to give $10 \mathrm{ng} \mathrm{ml}^{-1}$.

ITS: Sigma (catalogue no. I1884) prepare $50 \mathrm{ml}$ stock from one bottle and store stock frozen in working aliquots, dilute stock 1:1000 in final solution $=10 \mu \mathrm{l}$ per $10 \mathrm{ml}$

for maturation, particularly the importance and replacement of the FBS component with an appropriate combination of growth factors and other components that are present in the follicular milieu. FBS continues to be used with some success despite the concerns about potential transmission of infectious agents. From this point of view, HOM medium may be preferable for the clinical application of oocyte maturation in vitro.

A rather unusual variant of treatment for PCOS patients with irregular menstrual cycles was reported by Chian et al. $(1999 a, b)$ and involves oocyte maturation in vitro. The patients were given intravaginal progesterone $(300 \mathrm{mg}$ once a day) for 10 days to induce withdrawal bleeding and 10-14 days later were given 10000 iu hCG and the oocytes that were visible by transvaginal ultrasonography recovered from antral follicles. The oocytes were matured in vitro for $24-48 \mathrm{~h}$ in TCM 199 containing the patient's own serum (20\%), 25 mmol pyruvic acid $\mathrm{I}^{-1}$ and $75 \mathrm{miu}$ hMG. Of 25 patient treatment cycles, ten resulted in pregnancy (40\%) when an average of 2.9 embryos were transferred. The authors claimed that priming with hCG before oocyte recovery increased the developmental competence of the immature oocytes recovered. However, no data were provided to show that the oocytes were immature after hCG injection. Our observations reported earlier in this review show that the oocytes recovered are mature $36 \mathrm{~h}$ after hCG, even from follicles as small as $6 \mathrm{~mm}$ in diameter at the time of hCG injection. In a further study (Chian et al., 2000), the authors showed that $46 \%$ of oocytes were already maturing in hCG primed patients and the oocytes completed meiosis $12-24 \mathrm{~h}$ ahead of oocytes from unprimed (no hCG administration) patients. The final outcomes of fertilization, embryo development and pregnancy rates for hCG primed and unprimed patients were not significantly different.

\section{Oocyte maturation after superovulation of IVF patients with gonadotrophins ( $h M G, F S H$ and hCG)}

Normal methods for superovulation in human IVF entail the control of endogenous gonadotrophins, usually by suppression of their secretion and release from the pituitary by gonadotrophin releasing hormone $(\mathrm{GnRH})$ agonists or antagonists. Multiple follicular growth is induced by administration of exogenous FSH and the final phase of oocyte maturation is induced by hCG (Eldar-Geva et al., 1999). However, about $5-7 \%$ of oocytes recovered after superovulation for IVF are immature at the germinal vesicle (GV) stage and require further maturation in vitro (see Table 4). Some oocytes will complete maturation spontaneously in culture in vitro over 4-6 h before insemination (Osborn, 1993) and after being denuded of cumulus cells in preparation for fertilization by ICSI (De Vos et al., 1999). Fertilization may be lower with these oocytes and their cleavage and capacity to develop to term may be reduced (De Vos et al., 1999). The maturation of these oocytes may be considered to be delayed, and any reduced developmental competence compared with mature metaphase II oocytes may be related to the inability of the follicles to respond synchronously with other large follicles to hCG administration.

The time course for GVBD differs for GV stage oocytes recovered from superovulated IVF patients and untreated women (Cha and Chian, 1998). After $12 \mathrm{~h}$ of culture $80 \%$ of GV oocytes have undergone GVBD, whereas all the oocytes recovered from untreated patients still had intact GVs (Fig. 3). This leads to a disparity in the completion of nuclear maturation in the oocytes from both sources (Cha and Chian, 1998). About $75 \%$ of oocytes from superovulated patients reach metaphase II by $30 \mathrm{~h}$ of culture, whereas $75 \%$ of oocytes from untreated patients have extruded the first polar body by $42-45 \mathrm{~h}$ (Fig. 3). The difference in the onset of GVBD may be due to the priming of follicles by $\mathrm{FSH}$ and hCG before recovery of the 
oocytes. However, follicles that have immature oocytes after administration of large doses of hCG (500010000 iu hCG) must lack sufficient blood supply to receive the ovulatory stimulus or have insufficient $\mathrm{LH}$ receptors to induce the oocyte maturation response in vivo (reviewed by Salha et al., 1998b). Since many of the GV oocytes also have unexpanded cumuli, it is likely that insufficient FSH and $\mathrm{LH}$ is available to these follicles in vivo to induce oocyte maturation.

Oocytes considered to be immature by cumulus and corona cell expansion after superovulation of IVF patients can be matured in culture without gonadotrophin or steroid supplements (Veeck et al., 1983; Dandekar et al., 1991) but the culture medium usually contains the patient's own serum and occasionally granulosa cells recovered from the same follicle or from other follicles that contained a mature oocyte. There are numerous case reports of development to term after maturation of oocytes recovered from superovulated patients without any special additives to culture medium (Nagy et al., 1996; Edirisinghe et al., 1997; Tucker et al., 1998). Pregnancies have also been reported for IVF patients who were not given the final ovulating dose of hCG either by mistake (Liu et al., 1997) or to reduce the probability of ovarian hyperstimulation syndrome (OHSS) (Jaroudi et al., 1997; Coskun et al., 1998). In the former case, $50 \mathrm{iu} \mathrm{FSH} \mathrm{ml}{ }^{-1}$ and 50 iu hCG $\mathrm{ml}^{-1}$ in B2 Ménézo medium was used for oocyte maturation. In the latter case, hMG and hCG were also added to the culture medium for oocyte maturation $(75 \mathrm{miu}$ hMG $\mathrm{ml}^{-1}$ and 500 miu hCG ml-1 in human tubal fluid or Ham's F10 culture medium supplemented with $10 \%$ synthetic serum substitute; Irvine Scientific, Santa Ana, CA). Jaroudi et al. (1999) used this procedure and reported a pregnancy rate of $9.5 \%$ and an implantation rate of $4.5 \%$ per transferred embryo.

It is interesting that oocytes appear to mature spontaneously or in the presence of gonadotrophins when patients are treated as if to recover mature oocytes for conventional IVF. However, there is very limited application for maturation in vitro in association with superovulation except to use the few immature oocytes that are recovered, or as a precaution to prevent OHSS, although in overstimulated IVF patients other strategies are available for treating this potential problem.

\section{Pre-treatment of women with hMG or FSH for oocyte maturation}

Preliminary studies of the treatment of women for 1 or 3 days with recombinant human $\mathrm{FSH}$ (rhFSH) early in the follicular phase showed no difference in the recovery rate of oocytes, or oocyte maturation, fertilization or development in culture (Trounson et al., 1998). This finding was confirmed by Mikkelsen et al. (1999) who also treated women for 3 days with rhFSH (150 iu once a day, days 3-5 of the cycle) and found no improvement in any parameter of oocyte recovery, maturation or developmental

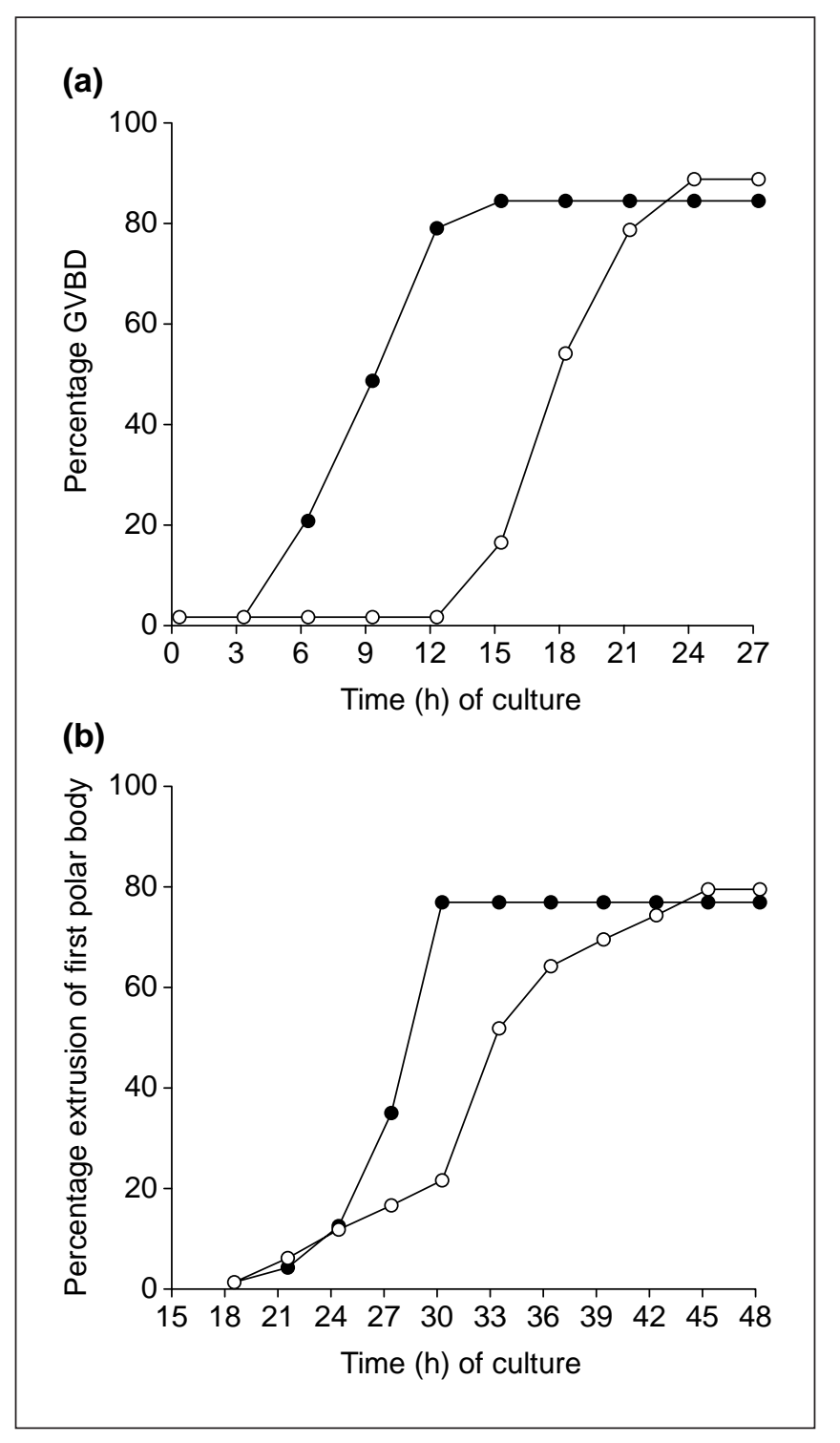

Fig. 3. Time course of (a) germinal vesicle breakdown (GVBD) and (b) the completion of maturation to metaphase II (extrusion of first polar body) in immature oocytes obtained from superovulated (stimulated, $\mathbf{0}$ ) and untreated patients (unstimulated, $\bigcirc$ ). (a) Stimulated $83.3 \%=30 / 36$; unstimulated $87.5 \%=35 / 40$. (b) Stimulated $75.0 \%=27 / 36$; unstimulated $77.5 \%=31 / 40$. Reproduced with permission from Cha and Chian (1998).

competence. Oocytes were matured in TCM 199 with 75 miu rhFSH ml-1, 500 miu hCG ml-1 and $10 \%$ patient's own serum from the day of oocyte recovery. Mikkelsen et al. (1999) claimed a benefit of reduced culture period for maturation (36 versus $48 \mathrm{~h}$ ) on implantation rates of embryos produced. However, this aspect was not tested in the same experiment. Implantation rate was 15\% for oocytes matured for $36 \mathrm{~h}$ and $7 \%$ for oocytes matured for $48 \mathrm{~h}$, for embryos transferred in the two experiments. No benefit of an abbreviated culture interval for maturing 
Table 4. Maturation, fertilization, embryo cleavage and pregnancy rates from in vitro matured human oocytes from cycles in which oocytes had been exposed to exogenous human chorionic gonadotrophin (hCG) in vivo

\begin{tabular}{|c|c|c|c|c|c|c|c|}
\hline $\begin{array}{l}\text { Number } \\
\text { of cycles }\end{array}$ & $\begin{array}{c}\text { Number of } \\
\text { immature } \\
\text { oocytes }\end{array}$ & $\begin{array}{l}\text { Resumption } \\
\text { of meiosis }\end{array}$ & $\begin{array}{c}\text { Maturation } \\
\text { (metaphase II) }\end{array}$ & Fertilization & $\begin{array}{l}\text { Embryo } \\
\text { cleavage }\end{array}$ & $\begin{array}{l}\text { Pregnancy from } \\
\text { transfer of } \\
\text { in vitro matured } \\
\text { embryos only }\end{array}$ & Study \\
\hline 44 & 74 & $97 \%$ & $86 \%$ & $85 \%$ & $90 \%$ & Singleton & Veeck et al., 1983 \\
\hline 40 & 65 & NR & $\begin{array}{l}36-74 \% \\
\text { dependent on } \\
\text { supplementation } \\
\text { with hMG }\end{array}$ & $36-64 \%$ & NR & NR & Prins et al., 1987 \\
\hline 85 & 132 & NR & NR & $\begin{array}{l}20-54 \% \\
\text { dependent on } \\
\text { co-culture with } \\
\text { granulosa cells }\end{array}$ & NR & NR & $\begin{array}{l}\text { Dandekar et al., } \\
1991\end{array}$ \\
\hline 66 & 254 & NR & $75-83 \%$ & $57-58 \%$ & $\begin{array}{l}79-90 \% \\
3-12 \% \text { blastocysts }\end{array}$ & ts $N R$ & Toth et al., 1994a \\
\hline 56 & 145 & $82-84 \%$ & $\begin{array}{l}38-82 \% \\
\text { dependent on } \\
\text { culture conditions }\end{array}$ & $44 \%$ & $100 \%$ & NR & $\begin{array}{l}\text { Janssenswillen } \\
\text { et al., } 1995\end{array}$ \\
\hline 1 & 14 & $100 \%$ & $64 \%$ & $78 \%$ & $71 \%$ & Singleton & Nagy et al., 1996 \\
\hline 1 & 5 & $100 \%$ & $100 \%$ & $80 \%$ & NR & Singleton & $\begin{array}{l}\text { Edirisinghe et al., } \\
\text { 1997a }\end{array}$ \\
\hline 26 & 80 & $50-100 \%$ & $\begin{array}{l}10-80 \% \\
\text { dependent on } \\
\pm \text { cumulus intact } \\
\text { and } \pm \text { sperm } \\
\text { co-culture }\end{array}$ & $50-87 \%$ & NR & NR & Fahri et al., 1997 \\
\hline 92 & 315 & $75-90 \%$ & $\begin{array}{l}\text { 34-64\% } \\
\text { dependent on } \\
\text { cumulus } \\
\text { denuded } \pm \text { EGF } \\
80-82 \% \\
\text { dependent } \\
\text { on cumulus } \\
\text { intact } \pm \text { EGF }\end{array}$ & $\begin{array}{l}59-66 \% \\
\pm \text { cumulus } \\
46-72 \% \\
+ \text { cumulus } \pm \text { EGF }\end{array}$ & $\begin{array}{l}48-89 \% \\
\pm \text { cumulus }\end{array}$ & NR & Goud et al., 1998 \\
\hline 59 & 101 & NR & $\begin{array}{l}30-32 \% \pm \\
\text { follicular fluid }\end{array}$ & $\begin{array}{l}62-77 \% \pm \\
\text { follicular fluid }\end{array}$ & NR & $\begin{array}{l}\text { Singleton } \\
\text { Singleton }^{\mathrm{a}}\end{array}$ & $\begin{array}{l}\text { Thornton et al., } \\
1998^{a}\end{array}$ \\
\hline 1 & 13 & NR & $67 \%$ & $100 \%$ & $100 \%$ & Singleton & $\begin{array}{l}\text { Tucker et al., } \\
1998^{a}\end{array}$ \\
\hline 2804 & 4716 & $\begin{array}{l}\text { Only GVBD } \\
\text { oocytes } \\
\text { studied }\end{array}$ & $27 \%$ by $4 \mathrm{~h}$ & $\begin{array}{l}53 \% \text { (less } \\
\text { than sibling } \\
\text { metaphase II } \\
\text { oocytes) }\end{array}$ & $\begin{array}{l}83 \% \\
\text { (comparable } \\
\text { to sibling } \\
\text { metaphase } \\
\text { Il oocytes) }\end{array}$ & Singleton & $\begin{array}{l}\text { De Vos et al., } \\
1999\end{array}$ \\
\hline 2 & 14 & NR & $79 \%$ & $100 \%$ & NR & $\begin{array}{l}\text { Singleton } \\
\text { Triplet }\end{array}$ & $\begin{array}{l}\text { Chian et al., } \\
\text { 1999a }\end{array}$ \\
\hline 25 & 249 & NR & $84 \%$ & $87 \%$ & $95 \%$ & $\begin{array}{l}\text { Singleton } \\
\text { Singleton } \\
\text { Twins } \\
\text { Five ongoing } \\
\text { Two miscarriage }\end{array}$ & $\begin{array}{l}\text { Chian et al., } \\
\text { 1999b }\end{array}$ \\
\hline 13 & 102 & NR & $84 \%$ & $91 \%$ & $95 \%$ & Five clinical & Chian et al., 2000 \\
\hline
\end{tabular}

alncludes cryopreservation of immature oocytes.

EGF: endothelial growth factor; GVBD: germinal vesicle breakdown; hMG: human menopausal gonadotrophin.

NR: not reported or not carried out. 

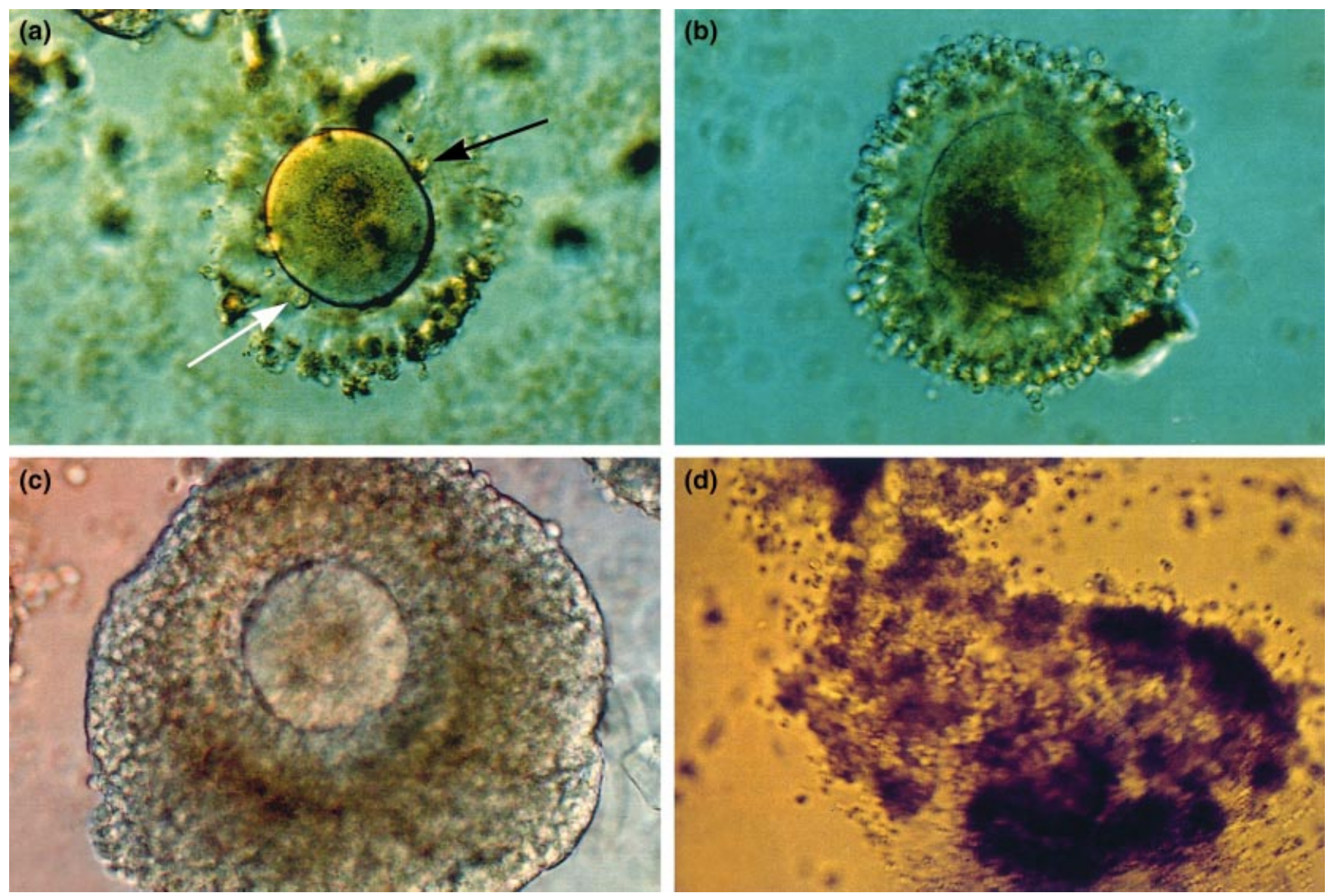

Fig. 4. Human in vitro matured oocytes. (a) In vitro matured oocyte with the first polar body visible (black arrow) and remnants of cumulus cell cytoplasmic processes (white arrow). Note expansion of the cumulus cells. (b) Germinal vesicle (GV) stage oocyte surrounded by cumulus cells. The oocyte cytoplasm is darker towards the pole opposite the GV. (c) Healthy GV stage oocyte deeply embedded in follicular granulosa cells. (d) GV stage oocyte embedded in dark atretic cumulus cells.

oocytes of untreated patients $(24,36$ or $48 \mathrm{~h})$ could be detected by Trounson et al. (1994, 1996).

Mikkelsen et al. (1999) did not observe any benefit of extending the rhFSH pre-treatment from 3 to 6 days to produce follicles $>10 \mathrm{~mm}$ in diameter. However, Wynn et al. (1998) administered 600 iu rhFSH to women over 5 days (300 iu on day 2, 150 iu on day 4 and 150 iu on day 6) for recovery of immature oocytes (day 7). A mean of 7.5 oocytes was recovered after rhFSH treatment compared with 5.2 oocytes from untreated women. Maturation to metaphase II was higher in rhFSH treated women (71\%) compared with untreated women (44\%) and hence more metaphase II oocytes resulted after rhFSH treatment (mean of 4.8 versus 2.1 for untreated women). The medium used was Eagles' minimum essential medium (EMEM) with a number of additives including $10 \mathrm{miu}$ rhFSH ml-1 and 100 miu hCG $\mathrm{ml}^{-1}$.

The failure to achieve a substantial improvement in the number and developmental competence of oocytes by pre-treatment with $\mathrm{FSH}$ indicates that maturation in vitro is not limited by the growth phase of follicles in the ovaries. Normally one or two follicles become dominant in the ovulatory cycle and the other antral follicles cease growth and will enter atresia as the follicular phase progresses. There seems little detectable difference in the maturational and developmental competence of oocytes recovered from the dominant follicle or those from atretic follicles, a surprisingly common observation that was first made by Moor and Trounson (1977) in sheep follicle culture. There would be no clinical application of pre-treatment of women with FSH to collect immature oocytes, unless a very substantial benefit could be demonstrated for maturation and development to term. Such a benefit appears to be unlikely from the present data. It would also seem unlikely that pre-treatment with FSH after removal of the dominant follicle, a protocol demonstrated to maximize bovine embryo production, would be similarly beneficial when applied to women (Bousquet et al., 1999; Fig. 2).

\section{Maturation of oocytes from untreated women}

The human ovary contains numerous antral follicles during the follicular and luteal phase of the ovulating cycle and during pregnancy. The harvest of immature 
Table 5. Maturation and embryo culture conditions in human in vitro maturation (IVM) cycles in which oocytes had not been exposed to exogenous human chorionic gonadotrophin (hCG) in vivo

\begin{tabular}{|c|c|c|c|c|c|c|}
\hline Source of oocytes & IVM culture medium & $\begin{array}{l}\text { IVM culture } \\
\text { conditions }\end{array}$ & $\begin{array}{l}\text { Maturation } \\
\text { time (h) }\end{array}$ & $\begin{array}{l}\text { Embryo } \\
\text { culture } \\
\text { medium }\end{array}$ & $\begin{array}{l}\text { Embryo } \\
\text { culture } \\
\text { time }(\mathrm{h})\end{array}$ & Authors \\
\hline $\begin{array}{l}\text { Ovarian resection } \\
\text { Oophorectomy }\end{array}$ & $\begin{array}{l}\text { Ham's F10 + } \\
\text { glutamine }+15 \% \\
\text { FBS + penicillin }\end{array}$ & $5 \% \mathrm{CO}_{2}$ in air & 43 & NR & NR & Tsuji et al., 1985 \\
\hline $\begin{array}{l}\text { Ovarian resection } \\
\text { Oophorectomy }\end{array}$ & $\mathrm{B}_{2}$ & $5 \% \mathrm{CO}_{2}$ in air & 48 & NR & NR & Lefevre et al., 1987 \\
\hline $\begin{array}{l}\text { Ovarian biopsy } \\
\text { Oophorectomy }\end{array}$ & $\begin{array}{l}\text { Ham's F10 } \\
+20 \% \text { FCS } / 50 \% \text { FF }\end{array}$ & NR & $32-48$ & $\begin{array}{l}\text { Ham's F10 + } \\
20 \% \text { FCS }\end{array}$ & $24-48$ & Cha et al., 1991 \\
\hline $\begin{array}{l}\text { Aspiration, laparotomy } \\
\text { Ovarian resection } \\
\text { Oophorectomy }\end{array}$ & $\mathrm{B}_{2} \pm \mathrm{EGF} \pm \mathrm{IGF}-\mathrm{I}$ & NR & $24-48$ & NR & NR & Gomez et al., 1993 \\
\hline $\begin{array}{l}\text { Aspiration, vaginal } \\
\text { ultrasonography } \\
\text { Polycystic ovaries }\end{array}$ & 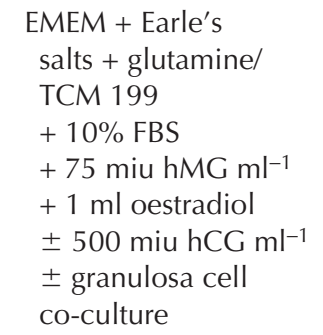 & $\begin{array}{l}\text { Microdrops under } \\
\text { paraffin oil } \\
1 \mathrm{ml} \text { in culture tubes } \\
1 \mathrm{ml} \text { in } \\
\text { co-culture dishes } \\
5 \% \mathrm{CO}_{2} \text { in air } / 5 \% \\
\mathrm{CO}_{2}, 5 \% \mathrm{O}_{2}, 90 \% \mathrm{~N}_{2}\end{array}$ & $2_{2}$ & $\begin{array}{l}\mathrm{HTF}+10 \% \\
\text { patient serum }\end{array}$ & $58-68$ & $\begin{array}{l}\text { Trounson et al., } \\
1994\end{array}$ \\
\hline $\begin{array}{l}\text { Aspiration, vaginal } \\
\text { ultrasonography } \\
\text { Polycystic ovaries }\end{array}$ & $\begin{array}{l}\text { TCM } 199+10 \% \\
\text { FBS + } 75 \text { miu } \\
\text { rhFSH ml } \\
+500 \text { miu hCG }^{-1} \\
\mathrm{ml}^{-1}+\text { pyruvate } \\
+ \text { penicillin }+ \\
\text { streptomycin }\end{array}$ & $\begin{array}{l}\text { Under silicon oil } \\
5 \% \mathrm{CO}_{2} \text { in air }\end{array}$ & $36-46$ & $\begin{array}{l}\mathrm{HTF}+10 \% \\
\text { patient serum or } \\
\mathrm{G} 1 / \mathrm{G} 2+\mathrm{BSA}\end{array}$ & 68-110 & Barnes et al., 1995ª \\
\hline $\begin{array}{l}\text { Aspiration, vaginal } \\
\text { ultrasonography } \\
\text { Polycystic ovaries and } \\
\text { normal ovaries }\end{array}$ & $\begin{array}{l}\text { TCM } 199+10 \% \text { FBS } \\
+75 \text { miu rhFSH } \mathrm{ml}^{-1} \\
+500 \text { miu hCG } \\
\mathrm{ml}^{-1}+\text { pyruvate } \\
+ \text { penicillin } \\
\text { + streptomycin }\end{array}$ & $\begin{array}{l}\text { Under silicon oil } \\
5 \% \mathrm{CO}_{2} \text { in air }\end{array}$ & NR & $\begin{array}{l}\mathrm{HTF}+10 \% \\
\text { patient serum }\end{array}$ & NR & Barnes et al., 1996 \\
\hline Oophorectomy & $\begin{array}{l}\text { Ham's F10 + 7.5\% } \\
\text { FBS } \pm 75 \text { miu } \\
\text { urofollitropin } \mathrm{ml}^{-1}\end{array}$ & $5 \% \mathrm{CO}_{2}$ in air & $24-72$ & NR & NR & Durinzi et al., 1997 \\
\hline $\begin{array}{l}\text { Aspiration, vaginal } \\
\text { ultrasonography }\end{array}$ & $\begin{array}{l}\mathrm{HTF}+10 \% \\
\mathrm{SSS}+75 \mathrm{miu} \\
\mathrm{hMG} \mathrm{\textrm {m } ^ { - 1 }} \\
+500 \mathrm{miu} \text { hCG } \\
\mathrm{ml}^{-1} \\
+ \text { granulosa cells }\end{array}$ & Under mineral oil & 48 & $\begin{array}{l}\mathrm{HTF}+10 \% \\
\text { SSS }+ \text { cumulus }+ \\
\text { granulosa cells }\end{array}$ & $\begin{array}{r}\approx 72 \\
+\end{array}$ & $\begin{array}{l}\text { Jaroudi et al., } \\
\text { 1997a }\end{array}$ \\
\hline $\begin{array}{l}\text { Aspiration, vaginal } \\
\text { ultrasonography } \\
\text { Gonadotrophin } \\
\text { stimulated ovaries }\end{array}$ & $\begin{array}{l}\mathrm{B}_{2}+50 \mathrm{iu} \mathrm{FSH} \mathrm{ml}-1 \\
+50 \mathrm{iu} \mathrm{hCG} \mathrm{ml}\end{array}$ & $\begin{array}{l}\text { Under paraffin oil } \\
5 \% \mathrm{CO}_{2} \text { in air }\end{array}$ & 48 & $\mathrm{~B}_{2}$ & $\begin{array}{l}48 \\
\text { frozen }\end{array}$ & Liu et al., 1997a \\
\hline $\begin{array}{l}\text { Aspiration, vaginal } \\
\text { ultrasonography } \\
\text { Oestradiol primed } \\
\text { ovaries }\end{array}$ & $\begin{array}{l}\text { EMEM/TCM } 199 \\
+1 \mathrm{ml} \mathrm{oestradiol} \\
+75 \mathrm{miu}^{2} \mathrm{FH} \mathrm{m} \mathrm{m}^{-1}+ \\
500 \mathrm{miu} \text { hCG ml} \\
+3 \% \mathrm{SSS}\end{array}$ & NR & 52 & $\mathrm{HTF}+6 \% \mathrm{SSS}$ & 72 & Russell et al., 1997 \\
\hline
\end{tabular}

Continued. 
Table 5. (Continued)

\begin{tabular}{|c|c|c|c|c|c|c|}
\hline Source of oocytes & IVM culture medium & $\begin{array}{l}\text { IVM culture } \\
\text { conditions }\end{array}$ & $\begin{array}{l}\text { Maturation } \\
\text { time (h) }\end{array}$ & $\begin{array}{l}\text { Embryo } \\
\text { culture } \\
\text { medium }\end{array}$ & $\begin{array}{l}\text { Embryo } \\
\text { culture } \\
\text { time }(\mathrm{h})\end{array}$ & Authors \\
\hline $\begin{array}{l}\text { Aspiration, vaginal } \\
\text { ultrasonography } \\
\text { Polycystic ovaries }\end{array}$ & $\begin{array}{l}\text { TCM } 199+20 \% \\
\text { FBS }+10 \text { iu PMSG ml-1 } \\
+10 \text { iu hCG } \text { ml }^{-1}\end{array}$ & NR & NR & NR & $\approx 48$ & $\begin{array}{l}\text { Cha and Chian, } \\
1998\end{array}$ \\
\hline $\begin{array}{l}\text { Aspiration, vaginal } \\
\text { ultrasonography } \\
\text { Gonadotrophin } \\
\text { stimulated ovaries }\end{array}$ & $\begin{array}{l}\text { HTF/Ham's F10 + } \\
10 \% \text { SSS + } 75 \text { miu } \\
\text { hMG ml } \text { m }^{-1}+500 \text { miu } \\
\text { hCG ml } \text { m }^{-1} \text { granulosa cells }\end{array}$ & Under paraffin oil & 44 & NR & NR & Coskun et al., 1998 \\
\hline $\begin{array}{l}\text { Aspiration, } \\
\text { Caesarean section }\end{array}$ & $\begin{array}{l}\text { HTF }+150 \text { miu hMG } \\
\mathrm{ml}^{-1}+1 \mu \text { gestradiol } \\
\mathrm{ml}^{-1}+10 \% \text { FCS }\end{array}$ & $\begin{array}{l}\text { Under mineral oil } \\
5 \% \mathrm{CO}_{2} \text { in air }\end{array}$ & $36-48$ & $\begin{array}{l}\text { HTF }+10 \% \\
\text { FCS } \pm \text { human } \\
\text { ampullary } \\
\text { epithelial cell } \\
\text { monolayer }\end{array}$ & $\approx 168$ & Hwu et al., 1998 \\
\hline $\begin{array}{l}\text { Aspiration, } \\
\text { laparoscopy/ } \\
\text { laparotomy } \\
\text { Oophorectomy }\end{array}$ & $\mathrm{HTF}+10 \% \mathrm{SSS}$ & $\begin{array}{l}\text { Under mineral oil } \\
5 \% \mathrm{CO}_{2} \text { in air }\end{array}$ & $24-48$ & NR & NR & $\begin{array}{l}\text { Whitacre et al., } \\
1998\end{array}$ \\
\hline $\begin{array}{l}\text { Aspiration, vaginal } \\
\text { ultrasonography } \\
\pm \text { gonadotrophin } \\
\text { 'primed' ovaries }\end{array}$ & $\begin{array}{l}\text { EMEM + Earle's salts } \\
+0.1 \% \text { HSA + pyruvate } \\
+ \text { penicillin + streptomycin } \\
\text { + insulin + transferrin } \\
\text { + selenium + glutamine } \\
+10 \text { miu rhFSH ml-1 } \\
\text { + } 100 \text { miu hCG ml-1 }\end{array}$ & $\begin{array}{l}\text { Under mineral oil } \\
5 \% \mathrm{CO}_{2} \text { in air }\end{array}$ & $24-52$ & NR & NR & Wynn et al., 1998 \\
\hline $\begin{array}{l}\text { Aspiration, vaginal } \\
\text { ultrasonography } \\
\text { Gonadotrophin } \\
\text { stimulated ovaries }\end{array}$ & 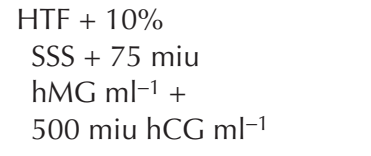 & Under mineral oil & 44 & $\begin{array}{l}\mathrm{HTF}+10 \% \\
\mathrm{SSS}+\text { cumulus/ } \\
\text { granulosa cells }\end{array}$ & $\approx 72$ & Jaroudi et al., 1999 \\
\hline $\begin{array}{l}\text { Aspiration, vaginal } \\
\text { ultrasonography }\end{array}$ & $\begin{array}{l}\text { TCM } 199+0.4 \% \\
\text { HSA + pyruvate } \\
+75 \text { miu rhFSH ml-1 } \\
+500 \text { miu hCG ml}^{-1} \\
+2 \mathrm{ng} \mathrm{EGF} \mathrm{ml}^{-1}+ \\
1 \mu \mathrm{g} \text { oestradiol ml-1 }\end{array}$ & $5 \% \mathrm{CO}_{2}$ in air & $24-36$ & $\begin{array}{l}\text { SIS IVF50: } \\
\text { S2 + human } \\
\text { endometrial } \\
\text { epithelial cells }\end{array}$ & $\geqslant 110$ & Cobo et al., 1999 \\
\hline $\begin{array}{l}\text { Aspiration, vaginal } \\
\text { ultrasonography } \\
\pm \text { gonadotrophin } \\
\text { 'primed' ovaries }\end{array}$ & $\begin{array}{l}\text { TCM } 199+\text { pyruvate } \\
+ \text { penicillin } \\
+ \text { streptomycin }+1 \mu \mathrm{g} \\
\text { oestradiol } \mathrm{ml}^{-1}+ \\
75 \text { miu rhFSH ml } \\
+500 \text { miu hCG ml}^{-1} \\
+10 \% \text { patient serum }\end{array}$ & $\begin{array}{l}\text { Under paraffin oil } \\
5 \% \mathrm{CO}_{2} \text { in air }\end{array}$ & $36-48$ & Medicult IVF & $\approx 48-72$ & $\begin{array}{l}\text { Mikkelsen et al., } \\
1999\end{array}$ \\
\hline $\begin{array}{l}\text { Aspiration, vaginal } \\
\text { ultrasonography } \\
\pm \text { hCG primed } \\
\text { ovaries }\end{array}$ & $\begin{array}{l}\text { TCM } 199+\text { pyruvate } \\
+75 \mathrm{miu} \mathrm{FSH} \mathrm{ml}^{-1} \\
+\mathrm{LH}+20 \% \mathrm{FBS}\end{array}$ & $5 \% \mathrm{CO}_{2}$ in air & 48 & Medicult IVF & $\approx 48-72$ & Chian et al., 2000 \\
\hline
\end{tabular}

${ }^{\mathrm{a} C}$ Case report.

$\mathrm{B}_{2}$ : Menezo's medium; BSA: bovine serum albumin; EGF: epidermal growth factor; EMEM: Eagle's minimal essential medium; FBS: fetal bovine serum; FCS: human fetal cord serum; FF: follicular fluid; hCG: human chorionic gonadotrophin; hMG: human menopausal gonadotrophin; HTF: human tubal fluid medium; HSA: human serum albumin; IGF-I: insulin-like growth factor I; SIS: Scandinavian IVF Sciences AB; SSS: synthetic serum supplement (Irvine Scientific, Santa Ana, CA); TCM 199: tissue culture medium 199.

'Primed' indicates a truncated course of treatment compared with routine IVF stimulation cycles.

NR: not reported or not carried out. 
Table 6. Maturation, fertilization, embryo cleavage and pregnancy rates from in vitro matured human oocytes from cycles in which oocytes had not been exposed to exogenous human chorionic gonadotrophin (hCG) in vivo

\begin{tabular}{|c|c|c|c|c|c|c|c|}
\hline $\begin{array}{l}\text { Number } \\
\text { of } \\
\text { cycles }\end{array}$ & $\begin{array}{c}\text { Number of } \\
\text { immature } \\
\text { oocytes }\end{array}$ & $\begin{array}{l}\text { Resumption } \\
\text { of meiosis }\end{array}$ & $\begin{array}{c}\text { Maturation } \\
\text { (metaphase II) }\end{array}$ & Fertilization & $\begin{array}{l}\text { Embryo } \\
\text { cleavage }\end{array}$ & Pregnancy & Study \\
\hline 90 & 96 & $\begin{array}{l}35-69 \% \\
\text { dependent } \\
\text { on size of } \\
\text { follicle and } \\
\text { cycle stage }\end{array}$ & $\begin{array}{l}\text { 9-35\% } \\
\text { dependent } \\
\text { on size of } \\
\text { follicle and } \\
\text { stage of cycle }\end{array}$ & NR & NR & NR & Tsuji et al., 1985 \\
\hline 11 & 24 & $\begin{array}{l}31-73 \% \\
\text { dependent } \\
\text { on state of } \\
\text { follicle atresia }\end{array}$ & NR & NR & NR & NR & Lefevre et al., 1987 \\
\hline 23 & 157 & NR & $\begin{array}{l}36-56 \% \\
\text { dependent on } \\
\text { culture medium } \\
\text { supplement }\end{array}$ & $32-81 \%$ IVF & $\begin{array}{l}78.7 \% \\
\text { normal } \\
\text { embryos }\end{array}$ & Triplets & Cha et al., 1991 \\
\hline 40 & 125 & $\begin{array}{l}33-75 \% \text { at } 24 \\
\text { and } 48 \mathrm{~h} \\
82-100 \% \text { at } 24 \\
\text { and } 48 \mathrm{~h} \text { with EGF } \\
88-100 \% \text { at } 24 \\
\text { and } 48 \mathrm{~h} \text { with } \\
\text { IGF-I }\end{array}$ & $\begin{array}{l}0-16 \% \text { at } 24 \\
\text { and } 48 \mathrm{~h} \\
20-55 \% \text { at } 24 \\
\text { and } 48 \mathrm{~h} \text { with EGF } \\
24-38 \% \text { at } 24 \\
\text { and } 48 \mathrm{~h} \text { with } \\
\text { IGF-I }\end{array}$ & NR & NR & NR & Gomez et al., 1993 \\
\hline 42 & 159 & $\begin{array}{l}81-100 \% \text { at } \\
21-22 \text { and } \\
48-54 \mathrm{~h}\end{array}$ & $\begin{array}{l}18-81 \% \\
\text { at } 23-25 \text { and } \\
48-54 \mathrm{~h}\end{array}$ & $41-45 \%$ IVF & Retarded & Singleton & $\begin{array}{l}\text { Trounson et al., } \\
1994\end{array}$ \\
\hline 1 & 13 & NR & $47-77 \%$ & $\begin{array}{l}0-80 \% \\
\text { IVF/ICSI }\end{array}$ & $\begin{array}{c}75-100 \%(68 h) \\
17 \%(110 h)\end{array}$ & Singleton & Barnes et al., 1995 \\
\hline 20 & 234 & NR & $\begin{array}{l}60-100 \% \\
\text { dependent on } \\
\text { menstrual cycle } \\
\text { regularity and } \\
\text { cumulus cover } \\
\text { of oocytes }\end{array}$ & $20-67 \%$ IVF & $\begin{array}{l}10-60 \% \\
\text { Retarded only } \\
\text { in irregular } \\
\text { cycles }\end{array}$ & NR & Barnes et al., 1996 \\
\hline 11 & 58 & $\begin{array}{l}79-90 \% \\
\text { dependent on } \\
\text { urofollitropin }\end{array}$ & $\begin{array}{l}38-59 \% \\
\text { dependent on } \\
\text { urofollitropin }\end{array}$ & NR & NR & NR & $\begin{array}{l}\text { Durinzi et al., } \\
1997\end{array}$ \\
\hline 1 & 10 & $100 \%$ & $90 \%$ & $78 \%$ ICSI & $100 \%$ & $\begin{array}{l}\text { Singleton } \\
\text { (death after } \\
\text { premature } \\
\text { delivery) }\end{array}$ & Jaroudi et al., 1997 \\
\hline 1 & 5 & $100 \%$ & $100 \%$ & $20 \%$ ICSI & $100 \%$ & Singleton & Liu et al., 1997 \\
\hline 14 & 161 & $N R$ & $\begin{array}{l}40-62 \% \\
\text { dependent on } \\
\text { time of oestradiol } \\
\text { follicular priming }\end{array}$ & $75 \%$ ICSI & $64-92 \%$ & Singleton & Russell et al., 1997 \\
\hline 72 & 832 & NR & $60 \%$ & $80 \%$ ICSI & $90 \%$ & $\begin{array}{l}\text { Twins } \\
15 \text { singletons }\end{array}$ & $\begin{array}{l}\text { Cha and Chian, } \\
1998\end{array}$ \\
\hline 20 & 162 & $78 \%$ & $66 \%$ & NR & NR & NR & Coskun et al., 1998 \\
\hline
\end{tabular}

Continued. 
Table 6. (Continued)

\begin{tabular}{|c|c|c|c|c|c|c|c|}
\hline $\begin{array}{l}\text { Number } \\
\text { of } \\
\text { cycles }\end{array}$ & $\begin{array}{l}\text { Number of } \\
\text { immature } \\
\text { oocytes }\end{array}$ & $\begin{array}{l}\text { Resumption } \\
\text { of meiosis }\end{array}$ & $\begin{array}{l}\text { Maturation } \\
\text { (metaphase II) }\end{array}$ & Fertilization & $\begin{array}{l}\text { Embryo } \\
\text { cleavage }\end{array}$ & Pregnancy & Study \\
\hline 51 & 268 & NR & $67 \%$ & $70 \%$ IVF & $\begin{array}{l}87-89 \% \\
\text { Comparable } \\
\text { development to } \\
\text { IVF for initial } \\
48 \mathrm{~h} \\
30 \% \text { blastocysts } \\
\text { in co-culture }\end{array}$ & S & Hwu et al., 1998 \\
\hline 88 & 289 & $\begin{array}{l}46-59 \% \text { at } \\
24 \text { and } 48 \mathrm{~h} \\
48-60 \% \\
\text { dependent on } \\
\text { source of oocytes } \\
54-61 \% \\
\text { dependent } \\
\text { on patient age } \\
44-63 \% \\
\text { dependent on } \\
\text { stage of menstrual } \\
\text { cycle }\end{array}$ & $\begin{array}{l}9 \text { and } 36 \% \text { at } \\
24 \text { and } 48 \mathrm{~h} \\
29-32 \% \\
\text { dependent on } \\
\text { source of oocytes } \\
30-35 \% \\
\text { dependent on } \\
\text { patient age } \\
31-33 \% \\
\text { dependent on } \\
\text { menstrual } \\
\text { cycle stage }\end{array}$ & $\begin{array}{l}\mathrm{NR} \\
\mathrm{s} \\
\mathrm{s}\end{array}$ & NR & NR & $\begin{array}{l}\text { Whitacre et al., } \\
1998\end{array}$ \\
\hline 26 & 160 & $\begin{array}{l}72-84 \% \\
\text { dependent on } \\
\text { 'priming' } \\
59-61 \% \text { at } 20 \\
\text { and } 54 \mathrm{~h}\end{array}$ & $\begin{array}{l}44-71 \% \\
\text { dependent on } \\
\text { 'priming' } \\
8-47 \% \text { at } 20 \\
\text { and } 54 \mathrm{~h}\end{array}$ & NR & NR & NR & Wynn et al., 1998 \\
\hline 21 & 171 & NR & $71 \%$ & $59 \%$ ICSI & $\begin{array}{l}75 \% \\
\text { Poorer quality } \\
\text { than IVF cycles }\end{array}$ & $\begin{array}{l}\text { Singleton J } \\
\text { Singleton } \\
\text { (death after } \\
\text { premature } \\
\text { delivery at } \\
24 \text { weeks) }\end{array}$ & Jaroudi et al., 1999 \\
\hline 19 & 112 & NR & $\begin{array}{l}37-52 \% \\
\text { dependent on } \\
\text { presence of } \\
\text { dominant follicle }\end{array}$ & $\begin{array}{l}\text { 66-88\% } \\
\text { ICSI }\end{array}$ & $\begin{array}{l}36-57 \% \\
\text { Development } \\
\text { to blastocyst }\end{array}$ & NR & Cobo et al., 1999 \\
\hline 32 & 115 & NR & $\begin{array}{l}71-81 \% \\
\text { dependent on } \\
\text { duration of } \\
\text { 'priming' }\end{array}$ & $\begin{array}{l}61-79 \% \\
\text { ICSI }\end{array}$ & $53-72 \%$ & $\begin{array}{l}\text { Two } \\
\text { singletons } \\
\text { delivered } \\
\text { Three } \\
\text { singletons } \\
\text { ongoing } \\
\text { One singletor } \\
\text { miscarried }\end{array}$ & $\begin{array}{l}\text { Mikkelsen et al., } \\
1999\end{array}$ \\
\hline 11 & 81 & NR & $69 \%$ & $84 \%$ & $96 \%$ & Three clinical & al Chian et al., 2000 \\
\hline
\end{tabular}

NR: not reported or not carried out.

EGF: epithelial growth factor; ICSI: intracytoplasmic sperm injection; IGF-I: insulin-like growth factor I.

oocytes from antral follicles visible in the ovarian cortex provides the opportunity to study the maturation process in vitro and to avoid the administration of gonadotrophins to women for collection of multiple oocytes. Reports to date of maturation in vitro of human oocytes from untreated women are summarized (Tables 5 and 6).
It was originally shown by Cha et al. (1991) that oocytes recovered from ovaries removed from women for various gynaecological conditions can be matured in culture in Ham's F10 medium with $20 \%$ fetal cord serum (FCS) or $50 \%$ follicular fluid from preovulatory follicles that contained mature metaphase II oocytes. Maturation in 


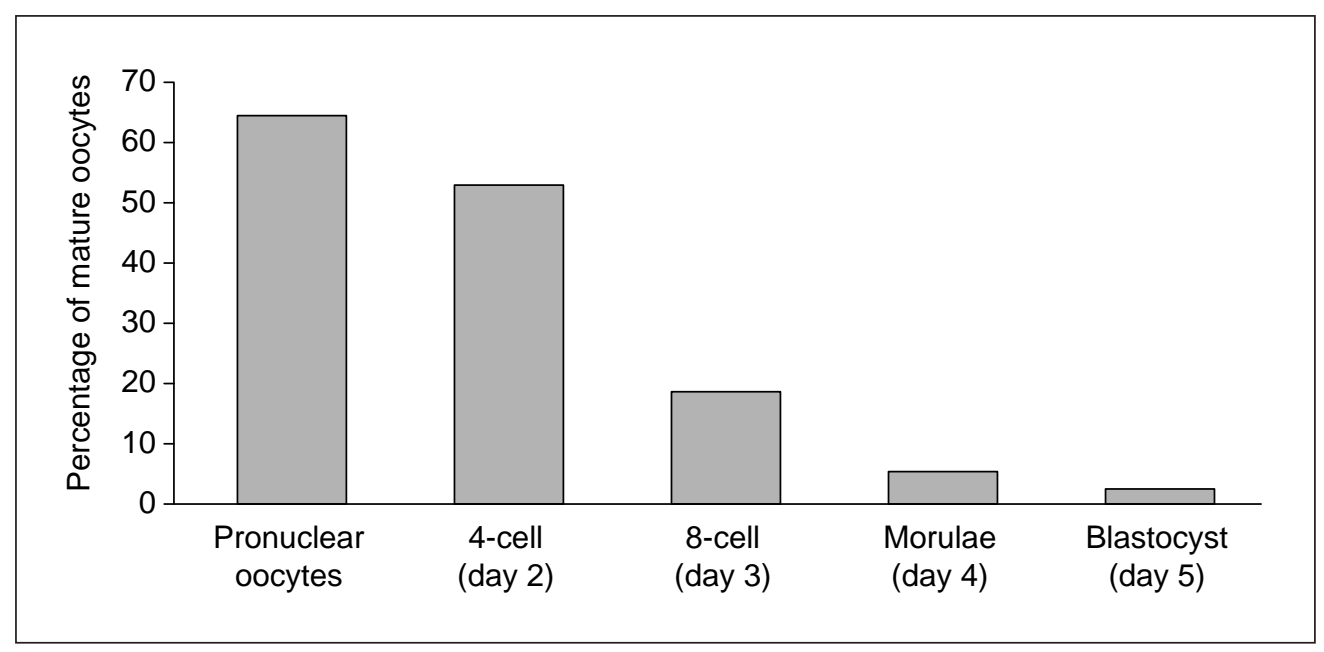

Fig. 5. Proportion of in vitro matured oocytes that underwent fertilization and developed to cleavage stage embryos, morulae and blastocysts in vitro. Oocytes were matured in TCM $199+$ gonadotrophins or Chang's medium for $48 \mathrm{~h}$, fertilized by intracytoplasmic sperm injection (ICSI) and cultured in Earle's medium with 10\% patient's serum. Reproduced with permission from Trounson et al. (1998).

medium with follicular fluid resulted in $56 \%$ metaphase II oocytes after $32-48 \mathrm{~h}$ and $81 \%$ of the mature oocytes underwent fertilization. Lower results were obtained with FCS (36\% maturation to metaphase II and 32\% fertilization). When five embryos were transferred to a patient, a triplet pregnancy resulted. No difference in oocyte maturational or developmental competence could be identified between oocytes recovered in the follicular or luteal phase of the ovulatory cycle.

The introduction of ultrasound guided oocyte retrieval of immature oocytes by Trounson et al. (1994) allowed greater access to growing follicles in the ovaries and the examination of an alternative to administration of high doses of gonadotrophins to women for superovulation. In EMEM with $10 \%$ FBS, 75 miu hMG ml-1, 500 miu hCG $\mathrm{ml}^{-1}$ and $1 \mu \mathrm{g}$ oestradiol $\mathrm{ml}^{-1}, 81 \%$ of oocytes matured to metaphase II by $48-54 \mathrm{~h}$ of culture. The replacement of EMEM with TCM 199 produced the same outcomes for maturation, fertilization and embryo development, including births from maturation in both media (Trounson et al., 1994; Barnes et al., 1995, 1996). These studies again confirmed that oocyte-cumulus health (tight cumuluscorona cover, loose or partly absent corona cover, denuded oocytes, obvious atresia in cumulus-corona cover; Fig. 4) had no obvious effect on maturational or developmental competence (Barnes et al., 1996). It was apparent that oocytes from women with regular ovulatory cycles had a better cleavage rate than those who were anovulatory or had irregular menstrual cycles (Barnes et al., 1996). Russell et al. (1997) claimed that administration of oestradiol to patients in the early to mid-follicular phase before recovery of immature oocytes, increases maturation, fertilization and their developmental competence. However, in controlled studies reported by Trounson et al. (1998) there was no benefit of oestrogen treatment of patients in any of the parameters examined. It is possible that prolonged oestrogen treatment may increase uterine receptivity for embryo implantation, although this remains to be proven.

In an interesting variation of natural cycle IVF, Thornton et al. (1998) recovered immature GV oocytes from follicles secondary to the one dominant follicle after hCG injection (10000 iu). These follicles were $\leqslant 12 \mathrm{~mm}$ and were matured in Ham's F10 + 50\% follicular fluid as described by Cha et al. (1991) or in standard culture medium. There was no difference in maturation rates in vitro $(30 \%$ and $32 \%$, respectively) or fertilization rates $(77 \%$ and $62 \%$, respectively). A birth resulted from the transfer of an embryo in the same cycle as the immature egg retrieval. An additional birth resulted from one of six transfers of cryopreserved embryos derived from oocytes matured in vitro. A similar approach was adopted by Chian et al. (1999a,b, 2000) for PCOS patients with irregular menstrual cycles, and good pregnancy rates were achieved using maturation medium with gonadotrophins and serum additives.

It has also been reported that oocytes recovered at the end of pregnancy (Caesarean section) can be matured in human tubal fluid (HTF) medium with 150 miu hMG ml-1, $10 \%$ FCS and $1 \mu \mathrm{g}$ oestradiol $\mathrm{ml}^{-1}$ (Hwu et al., 1998). Embryos failed to cleave beyond two to six cells in HTF medium with $10 \%$ FCS, but $26 \%$ of the pronuclear zygotes developed to blastocysts in human ampullary epithelial cell co-culture. This finding again demonstrates the flexibility of the origins of oocytes for maturation and underlines the importance of factors intrinsic to oocyte nuclear and cytoplasmic health for developmental competence. Providing culture medium and culture conditions are appropriate and suitable for maintaining the essential metabolism, growth and molecular expression patterns, a 
viable embryo can be obtained from a wide range of physiological and endocrine states. The challenge is to recognize the key elements intrinsic to oocyte maturational competence and to ensure that these are catered for in the interventions required for oocyte maturation in vitro. A recent examination of oocytes recovered after superovulation in humans, or after ovulation in mice, for molecular markers of apoptosis does not support the hypothesis that apoptosis is responsible for fertilization and developmental abnormalities (Van Blerkom and Davis, 1998). Hence the cytoplasmic and chromosomal defects that occur in human oocytes are unlikely to be preprogrammed at least by apoptotic mechanisms. The occurrence of these defects may be due to interventions that interrupt the completion of essential cellular processes and interfere with messages from support cells required for molecular and cytoplasmic maturation events.

\section{Developmental competence of in vitro matured oocytes}

Nuclear maturation, the resumption of meiosis and completion of the first meiotic division, occurs in vitro for all species studied to date. Significant numbers of immature oocytes can be matured to metaphase II. Subsequent fertilization, cleavage and development to viable offspring vary according to the species studied. However, aberrations in cytoplasmic maturation are more likely to be apparent as failure in later stages of development (Moor et al., 1998). It is of interest to note the improved rates of fertilization and embryo development and viability after administering a priming dose of hCG to patients, and further research is needed to determine the physiological mechanisms involved in the apparent improvement in cytoplasmic maturation of human oocytes in vitro.

Recently, Anderiesz et al. (2000a) showed that exposure of cattle and human oocytes to a 1:10 ratio of $\mathrm{FSH}: \mathrm{LH}$ (1 iu rhFSH ml-1 and $10 \mathrm{iu}$ rhLH $\mathrm{ml}^{-1}$ ) resulted in significantly higher developmental competence evident by increased development to the blastocyst stage in vitro compared with FSH alone (1 iu rhFSH ml-1) or no gonadotrophins. In the human maturation system, FSH (1 iu rhFSH ml-1 in TCM $199+2 \mathrm{mg}$ human serum albumin $\mathrm{ml}^{-1}$ ) was used for the first $24 \mathrm{~h}$ of culture and both 1 iu $\mathrm{FSH} \mathrm{ml} \mathrm{m}^{-1}$ and $10 \mathrm{iu} \mathrm{LH} \mathrm{ml}^{-1}$ were included for the remaining $24 \mathrm{~h}$ of culture to complete maturation. The biphasic addition of gonadotrophins may enable the maturation of $\mathrm{LH}$ receptors on cumulus and granulosa cells and improve their responsiveness to $\mathrm{LH}$ in the second culture phase. In these experiments, $24 \%$ of the fertilized oocytes developed to blastocysts in vitro and no blastocysts were obtained in maturation medium containing FSH alone or no gonadotrophins. Further experiments are needed to confirm the benefit of biphasic exposure of human oocytes to gonadotrophins and to determine the mechanism responsible for improved development of embryos. Development of bovine blastocysts was highest $(24 \%)$ in medium with an
FSH:LH ratio of $1: 10$, but since these blastocysts mature within $24 \mathrm{~h}$, biphasic exposure to gonadotrophins was not examined.

It is important that evaluation of oocyte maturation in humans includes an adequate assessment of developmental competence in vivo or in vitro. Very few studies of in vitro matured human oocytes have included an assessment of development to the blastocyst stage at which stage it can be revealed that preimplantation development is seriously compromised (see for example Fig. 5). Barnes et al. (1995) were the first to report successful development to the blastocyst stage in sequential culture medium designed specifically to optimize blastocyst development. A pregnancy resulted from the transfer of a single blastocyst after assisted hatching. However, only one of six embryos produced in this case study was competent to develop to the blastocyst stage. Hwu et al. (1998) demonstrated that embryos derived from in vitro matured oocytes when cultured in HTF culture medium alone arrest at the 2- to 16-cell stage of development. However, when embryos are co-cultured with human ampullary cells, 30\% of zygotes are capable of developing to the blastocyst stage. Cobo et al. (1999) similarly reported high rates of development of embryos derived from in vitro matured oocytes to the blastocyst stage (49\%) when embryos were co-cultured with endometrial epithelial cells. These recent reports compare favourably with the proportion of zygotes developing to the blastocyst stage in the absence of co-cultured cells from in vivo matured oocytes harvested from stimulated cycles.

\section{Molecular checkpoint controls in oocyte maturation}

The meiotic cell cycle is a dynamic system that functions via an elaborate sequence of highly ordered and interrelated events. Mammalian oocytes are arrested at the G2phase of the cell cycle, specifically at the dictyate stage of prophase in the first meiotic division. The resumption of oocyte maturation releases oocytes from this developmental arrest and re-initiates meiosis. The meiotic cell cycle then proceeds through two consecutive M-phases, which result in a reduction in the maternal genome. The passage through the cell cycle is regulated by checkpoints and molecular controls.

\section{Checkpoint controls}

Cell cycle checkpoints are genetically encoded controls and biochemical pathways that represent an important mechanism in cell cycle progression as they impose delays in the cell cycle to ensure the systematic completion of each cell cycle phase before the initiation of the next phase (Hartwell and Weinert, 1989). In somatic cells, there are three major checkpoints, which are present at G1, G2 and M-phase and specifically monitor cell size, DNA replication, DNA damage and spindle abnormalities. 
Table 7. Checkpoints responsive to DNA replication

\begin{tabular}{|c|c|c|c|c|}
\hline Checkpoints & Species & $\begin{array}{l}\text { Gene/gene } \\
\text { product }\end{array}$ & Function & Study \\
\hline $\begin{array}{l}\text { Checkpoints responsive } \\
\text { to DNA replication }\end{array}$ & Drosophila & GRP & $\begin{array}{l}\text { Delays mitosis in response to inhibition } \\
\text { of DNA replication }\end{array}$ & Fogarty et al., 1997 \\
\hline $\begin{array}{l}\text { Checkpoints responsive } \\
\text { to DNA replication }\end{array}$ & Human & p53 & $\begin{array}{l}\text { Prevents G1 to S-phase transition after aberrant } \\
\text { mitosis } \\
\text { Prevents DNA re-replication }\end{array}$ & $\begin{array}{l}\text { Casenghi et al., } 1999 \\
\text { Di Leonardo et al., } \\
1997\end{array}$ \\
\hline Genes homologous to yeast & Mouse & HUS1 & Function in checkpoint control to be determined & Weiss et al., 1999 \\
\hline $\begin{array}{l}\text { DNA replication checkpoint } \\
\text { genes }\end{array}$ & & RAD1 & $\begin{array}{l}\text { Biological function as checkpoint remains to be } \\
\text { determined }\end{array}$ & Parker et al., 1998a \\
\hline $\begin{array}{l}\text { Genes homologous to yeast } \\
\text { DNA replication checkpoint } \\
\text { genes }\end{array}$ & Mouse & RAD17 & $\begin{array}{l}\text { Shares sequence homology with } S \text {. pombe } \\
\text { Rad } 17 \text { protein: function in cell cycle checkpoints } \\
\text { to be determined }\end{array}$ & Bluyssen et al., 1999 \\
\hline \multirow[t]{3}{*}{$\begin{array}{l}\text { Genes homologous to yeast } \\
\text { DNA replication checkpoint } \\
\text { genes }\end{array}$} & Human & RAD17 & $\begin{array}{l}\text { Shares sequence homology with } S \text {. pombe } \\
\text { Rad } 17 \text { protein: function in cell cycle checkpoints } \\
\text { to be determined }\end{array}$ & $\begin{array}{l}\text { Parker et al., 1998b } \\
\text { Bluyssen et al., } 1999\end{array}$ \\
\hline & & RAD1 & $\begin{array}{l}\text { Shares sequence homology with } S \text {. pombe } \\
\text { rad1 + checkpoint }\end{array}$ & $\begin{array}{l}\text { Parker et al., 1998a } \\
\text { Marathi et al., } 1998\end{array}$ \\
\hline & & RAD9 & $\begin{array}{l}\text { Shares sequence homology with } S \text {. pombe } \\
\text { Functions as a checkpoint for a block in } \\
\text { replication }\end{array}$ & $\begin{array}{l}\text { Lieberman et al., } \\
1996\end{array}$ \\
\hline
\end{tabular}

Table 8. Checkpoints responsive to DNA damage

\begin{tabular}{|c|c|c|c|c|}
\hline Checkpoints & Species & $\begin{array}{l}\text { Gene/gene } \\
\text { product }\end{array}$ & Function & Study \\
\hline $\begin{array}{l}\text { Checkpoints responsive } \\
\text { to DNA damage }\end{array}$ & Drosophila & GRP & Involved in checkpoint pathway for DNA damage & Fogarty et al., 1997 \\
\hline $\begin{array}{l}\text { Checkpoints responsive } \\
\text { to DNA damage }\end{array}$ & Human & $\begin{array}{l}\text { RAD9 } \\
\text { RAD1 } \\
\text { HUS1 }\end{array}$ & $\begin{array}{l}\text { Form a protein complex that functions as } \\
\text { checkpoint for DNA damage }\end{array}$ & $\begin{array}{l}\text { Volkmer and Karnitz, } \\
1999\end{array}$ \\
\hline $\begin{array}{l}\text { Checkpoints responsive } \\
\text { to DNA damage }\end{array}$ & Human & p53 & Arrests cell cycle at both the G1 and G2/M-phase & Agarwal et al., 1995 \\
\hline $\begin{array}{l}\text { Checkpoints responsive } \\
\text { to DNA damage }\end{array}$ & Human & RAD1 & Involved in checkpoint control after DNA damage & $\begin{array}{l}\text { Freire et al., } 1998 \\
\text { Parker et al., } 1998 \mathrm{~b}\end{array}$ \\
\hline $\begin{array}{l}\text { Genes homologous to yeast } \\
\text { DNA damage checkpoints }\end{array}$ & Mouse & HUS1 & Function in checkpoint control to be determined & Weiss et al., 1999 \\
\hline $\begin{array}{l}\text { Genes homologous to yeast } \\
\text { DNA damage checkpoints }\end{array}$ & Mouse & RAD17 & $\begin{array}{l}\text { Share homology with S. pombe rad } 17+ \\
\text { checkpoint gene }\end{array}$ & Bluyssen et al., 1999 \\
\hline $\begin{array}{l}\text { Genes homologous to yeast } \\
\text { DNA damage checkpoints }\end{array}$ & Human & RAD17 & $\begin{array}{l}\text { Share homology with S. pombe rad } 17+ \\
\text { checkpoint gene }\end{array}$ & $\begin{array}{l}\text { Parker et al., } 1998 \mathrm{~b} \\
\text { Bluyssen et al., } 1999\end{array}$ \\
\hline
\end{tabular}

\section{Checkpoints responsive to cell size}

Human oocytes must reach a critical size before they gain the ability to progress from the G2 to the M-phase. Whether the inability of small oocytes to progress through the G2-phase to M-phase is due to checkpoints responsive to cell size is unclear. Studies by Canipari et al. (1984) indicate that it is cell maturity rather than cell size that may govern meiotic progression. Alternatively, the inhibition of meiotic maturation in small oocytes may be due to a deficiency in products required for meiotic progression.

\section{Checkpoints responsive to DNA replication}

Genes have been identified that function as checkpoints for DNA damage and arrest, or delay cell cycle progression until DNA replication is complete (Table 7). Fulka et al. (1994, 1995a) demonstrated that the G2 to M-phase transition in murine oocytes is not influenced by the presence of unreplicated or replicating DNA. Although the genes associated with the checkpoint monitoring DNA replication have not been investigated directly in mammalian oocytes, current data indicate that the replication 
Table 9. Spindle associated checkpoints

\begin{tabular}{|c|c|c|c|c|}
\hline Checkpoints & Species & $\begin{array}{l}\text { Gene/gene } \\
\text { product }\end{array}$ & Function & Study \\
\hline Spindle sensitive checkpoint & Drosophila & BUB3 & $\begin{array}{l}\text { Associates with BUB1 to form a multi-protein } \\
\text { spindle assembly checkpoint }\end{array}$ & Basu et al., 1998 \\
\hline Spindle sensitive checkpoint & Drosophila & BUB1 & $\begin{array}{l}\text { Demonstrates that BUB1 is an important } \\
\text { component of spindle checkpoint in higher } \\
\text { eukaryotes }\end{array}$ & Basu et al., 1999 \\
\hline Spindle sensitive checkpoint & $\begin{array}{l}\text { Mouse } \\
\text { Mouse }\end{array}$ & $\begin{array}{l}\text { BUB1 } \\
\text { p53 }\end{array}$ & $\begin{array}{l}\text { Checkpoint response to spindle damage } \\
\text { Checkpoint ensures the maintenance of diploidy } \\
\text { Monitors disruption of the mitotic spindle }\end{array}$ & $\begin{array}{l}\text { Taylor and McKeon, } \\
1997 \\
\text { Cross et al., } 1995 \\
\text { Lanni and Jacks, } 1998\end{array}$ \\
\hline Spindle sensitive checkpoint & $\begin{array}{l}\text { Human } \\
\text { Human }\end{array}$ & $\begin{array}{l}\text { MAD2 } \\
\text { hBUB1 } \\
\text { and } \\
\text { hBUBR1 } \\
\text { kinases }\end{array}$ & $\begin{array}{l}\text { Monitors spindle-kinetochore attachment } \\
\text { Component of spindle checkpoint pathway } \\
\text { Monitor kinetochore-microtubule interactions } \\
\text { Function in checkpoint that monitors chromosome } \\
\text { alignment }\end{array}$ & $\begin{array}{l}\text { Li and Benezra, } 1996 \\
\text { Ouyang et al., } 1998 \\
\text { Jablonski et al., } 1998\end{array}$ \\
\hline
\end{tabular}

responsive checkpoints that function during mitosis do not function during oocyte meiosis (Fulka et al., 1994). On the basis of these findings it is possible that human oocytes also lack the checkpoints responsive to DNA replication.

\section{Checkpoints responsive to DNA damage}

Mammalian homologues to the yeast genes involved in the DNA damage checkpoints have been identified (Table 8) and are thought to participate in the same checkpoint functions as their yeast counterparts. Human oocytes have not been examined directly for the presence and function of these highly conserved DNA damage checkpoints. However, Fulka et al. (1997) demonstrated that the presence of damaged chromatin did not prevent the progression of meiosis in fused mouse oocytes. Therefore, it appears that DNA damage checkpoints may be either functionally inactive or absent during mammalian oocyte meiosis (Fulka et al., 1994, 1997).

\section{Spindle sensitive checkpoints}

Gene homologues to the spindle-sensitive checkpoints of yeast have been isolated in somatic cells of higher species (Table 9). However, relatively few studies have examined the presence of spindle associated checkpoints in the meiotic cell cycle of oocytes (Fulka et al., 1994, 1995a; LeMarie-Adkins et al., 1997; Cross and Smythe, 1998). Xenopus oocytes were shown to contain a spindle assembly checkpoint, part of which was p42 MAP kinase (Cross and Smythe, 1998). Fulka et al. (1994, 1995b) demonstrated the presence of checkpoints in murine M-phase oocytes that can delay or accelerate meiotic progression, but LeMarie-Adkins et al. (1997) found that the checkpoint mechanism that functions at the metaphase to anaphase transition was absent in mouse oocytes.

\section{Molecular control of oocyte maturation}

\section{Maturation promoting factor/M-phase promoting factor (MPF)}

In addition to checkpoint controls, cell cycle progression is also regulated by endogenous products. The most common and widely studied factor in the area of cell cycle progression is maturation promoting factor (MPF). The original research by Masui and Markert (1971) led to the discovery that an activity in the cytoplasm of mature amphibian oocytes could induce meiosis when injected into G2 arrested frog oocytes. This activity was found to be MPF and it is now widely accepted that MPF is the primary molecule involved in meiotic cell cycle progression and the factor responsible for $\mathrm{M}$-phase induction in all eukaryotic cells.

MPF is a serine-threonine kinase protein heterodimer composed of a catalytic subunit, p34 ${ }^{\mathrm{cdc} 2}$, and a regulatory subunit, cyclin B (Labbe et al., 1989; Pines and Hunter, 1989; Gautier et al., 1990). During the cell cycle, MPF activity is regulated by the phosphorylation-dephosphorylation of p34cdc2 and its association with cyclin B (Clarke and Karsenti, 1991). Specifically, MPF activation involves the association of cyclin B and p34cdc2 and selective dephosphorylation of $\mathrm{p} 34^{\mathrm{cdc} 2}$ on two residues, tyrosine 15 (Tyr15) and threonine 14 (Thr14) (Gautier et al., 1988, 1990; Dunphy and Newport, 1989). This dephosphorylation is mediated by the $c d c 25$ and nim1 genes (Russell and Nurse, 1986; Gautier et al., 1991). In oocytes, MPF activation occurs initially at the G2 to M-phase transition. However, before the induction of $M$-phase, p34 cdc2 and cyclin B are present as pre-MPF, a bound and p34cdc2 phosphorylated protein heterodimer, and are present in this inactivated state because of interaction with the WEE1 gene (Parker et al., 1991) (Fig. 6). 


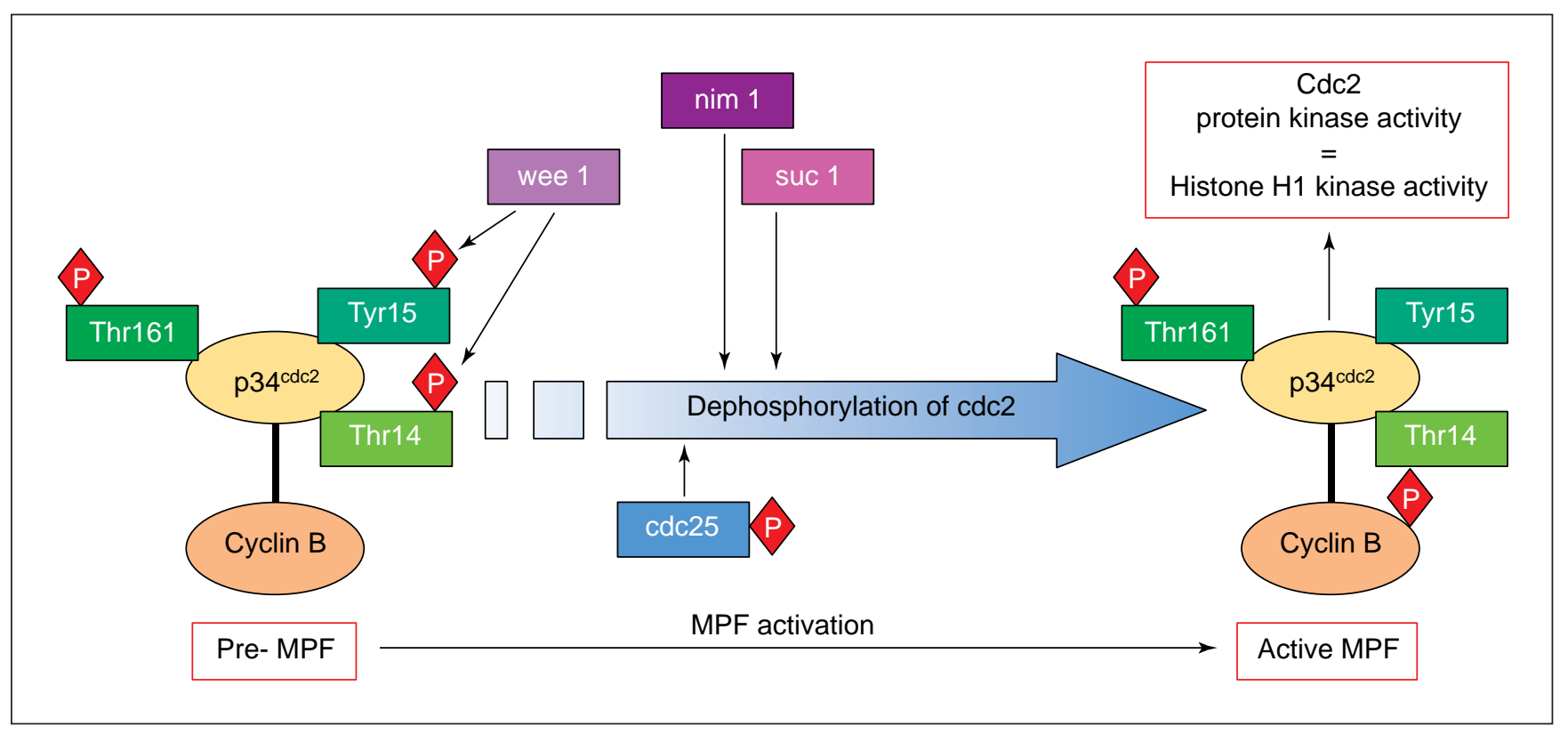

Fig. 6. Diagrammatic representation of the molecular structure and activation of maturation promoting factor (MPF). MPF is shown as a heterodimer composed of p34 cdc2 and cyclin B. In its pre-MPF state, the MPF heterodimer is phosphorylated on tyrosine 15 (Tyr15) and threonine 14 (Thr14). Threonine 14 and tyrosine 15 phosphorylation is due to the action of hypo-phosphorylated wee1. Then activation of MPF is primarily due to the interplay between cdc25 and nim 1 and wee1. The phosphorylated form of cdc25 is responsible for dephosphorylating the cdc2 protein on Tyr15 and Thr14, thus activating MPF. Hypo-phosphorylated wee1 prevents MPF activation by maintaining the Tyr15 and Thr14 residues of the cdc2 protein in a phosphorylated form. Nim1 maintains wee1 in a hyper-phosphorylated form that is unable to phosphorylate the Tyr15 and Thr14 residues of the cdc2 protein and thereby prevents wee 1 from holding MPF in a phosphorylated and inactive form. The active MPF molecule is dephosphorylated on Tyr15 and Thr14 of the cdc2 protein and the cyclin protein is phosphorylated. The active form of MPF displays cdc2 kinase activity, known as histone $\mathrm{H} 1$ kinase activity.

Cyclic MPF activity is a characteristic feature of oocytes and is attributable to the periodic activation and inactivation of the MPF heterodimer. MPF activity is detected just before, or concomitantly with, GVBD. MPF activity increases until metaphase I and decreases during the anaphase to telophase transition. The activity increases again until the oocyte reaches metaphase II, and is maintained at a high level by the interaction of cytostatic factor (CSF) and the viral oncogene c-mos until fertilization. Inactivation of MPF results in exit from metaphase, and during oocyte maturation MPF inactivation occurs at the transition of metaphase I to anaphase I and again at fertilization. P34cdc2 phosphorylation (Dorée et al., 1989) and cyclin degradation (Murray et al., 1989) are both required for MPF inactivation. However, despite the fact that both events are required for the cessation of $\mathrm{M}$-phase, the proteolytic destruction of cyclin B is seen as the principal event associated with the inactivation of MPF activity (Glotzer et al., 1991).

Cyclin destruction requires the presence of intact microtubules and occurs via ubiquitin-mediated proteolysis, a process that involves the attachment of ubiquitin molecules to the cyclin and is mediated in oocytes by three enzymes, E1, E2-C and E3 (Hershko et al., 1994). The ubiquinated cyclin is presented to the proteasome for degradation. The factors that activate the cyclin proteolytic pathway have not yet been fully elucidated. However, it has been demonstrated that cyclin degradation can be triggered by cdc2 (Felix et al., 1990; Hershko et al., 1994). Alternatively, the calcium, calmodulin, CaM kinase II pathway presents itself as an alternative candidate for initiating cyclin degradation because the calcium ionophore has been demonstrated to activate the proteasome (Kawahara and Yokosawa, 1994) and CaM kinase II activates cyclin destruction and mos and CSF degradation (Whitaker, 1996). The calcium, calmodulin, CaM kinase II pathway probably represents the mechanism by which MPF is inactivated at fertilization.

MPF is activated in vivo at the onset of oocyte maturation in response to an endogenous LH surge. Mammalian oocytes resume meiotic maturation spontaneously in vitro upon liberation from the ovarian follicle. Our studies show that in vitro maturation of human oocytes activates MPF activity, as evidenced by the increase in histone $\mathrm{H} 1$ kinase activity at metaphase II (Fig. 7). This finding demonstrates that MPF is activated in vitro in a manner similar to that for oocytes in vivo.

\section{C-mos}

c-mos is a proto-oncogene originally identified as the transforming gene of the Moloney murine sarcoma virus 


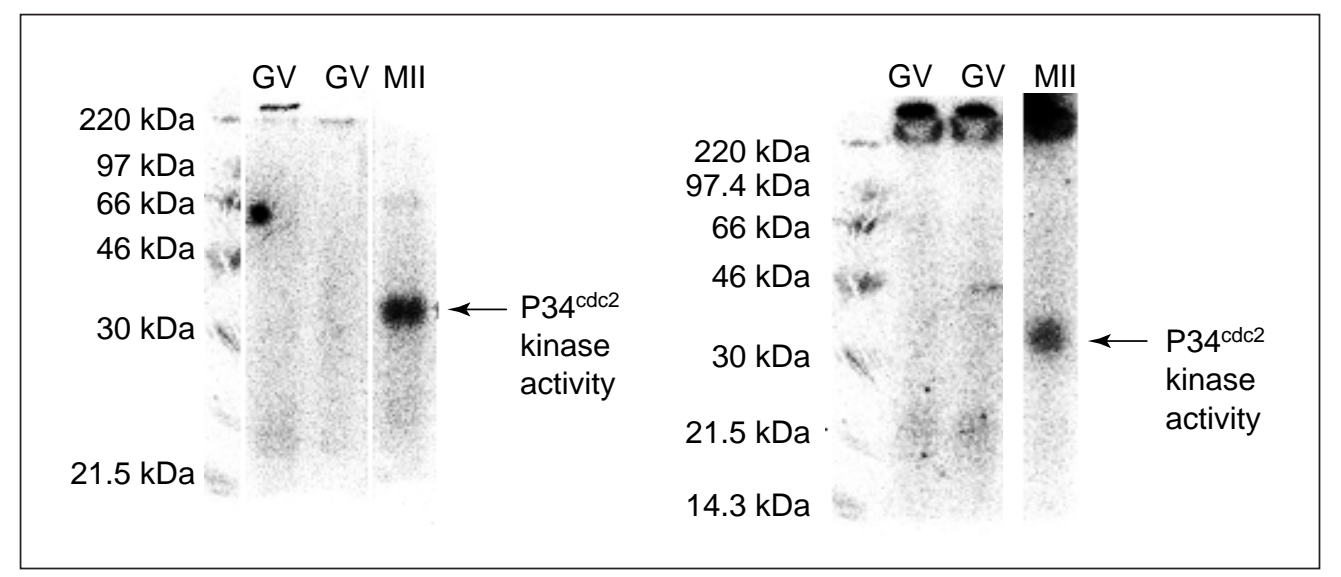

Fig. 7. Maturation promoting factor (MPF) activity in single germinal vesicle stage (GV) and metaphase II stage (MII) human oocytes. The oocytes were retrieved from women who had not received exogenous gonadotrophin treatment and the metaphase II oocytes were matured in vitro.

(Frankel and Fischinger, 1976). The c-mos proto-oncogene encodes a serine-threonine protein kinase (mos), which is expressed in oocytes. In the oocyte, mos is involved in several aspects of oocyte maturation. Mos has been demonstrated to phosphorylate cyclin B (Roy et al., 1990) and thereby affects cyclin stability (O'Keefe et al., 1991; Xu et al., 1992) and MPF activity. As part of the CSF complex, mos is involved in the maintenance of metaphase II arrest in mammalian oocytes and similarly, in Xenopus oocytes, mos has been implicated in the pathway that is involved in metaphase arrest (Kosako et al., 1994). In Xenopus, murine and bovine oocytes, mos activates mitogen activated protein (MAP) kinase (Nebreda and Hunt, 1993; Fissore et al., 1996; Verlhac et al., 1996). In addition, mos initiates and regulates meiotic maturation in Xenopus oocytes (Sagata et al., 1988; Roy et al., 1996) and has been shown to participate in, but is not essential for, murine oocyte maturation (O'Keefe et al., 1989; Araki et al., 1996). However, it is important for murine oocyte spindle and chromosome morphology, assembly and function (Zhao et al., 1991; Verlhac et al., 1996).

Mos has been detected in human oocytes (Pal et al., 1994; Heikinheimo et al., 1995, 1996) and its expression is restricted to the oocyte, as both the mos protein and mRNA are degraded during embryonic development (Heikinheimo et al., 1995). Although the action of mos during human oocyte maturation in vitro has not been investigated directly, it is likely to play a role in the regulation of meiotic maturation by interacting with cyclin B and CSF to stabilize MPF and maintain meiotic arrest, as well as participate in the activation of MAP kinase.

\section{Mitogen activated protein (MAP) kinase}

MAP kinase, which is alternatively known as extracellular regulated kinase (ERK), is a serine-threonine kinase that is activated via a protein kinase cascade at the onset of oocyte maturation in Xenopus (Haccard et al., 1990), mouse (Verlhac et al., 1993) and pig (Inoue et al., 1995) oocytes. MAP kinase activity (ERK) is associated with the induction of meiosis in Xenopus oocytes (Haccard et al., 1995) and although activated at the onset of oocyte maturation in mice, MAP kinase is not necessarily required for GVBD in mouse oocytes (Sun et al., 1999a). However, MAP kinase activity is associated with a plethora of cytoplasmic events including the regulation of microtubule dynamics, spindle assembly and chromosome condensation (Verlhac et al., 1993, 1994; Dedieu et al., 1996). In most oocytes (clam, starfish and ascidian oocytes are the notable exceptions), high concentrations of MAP kinase are maintained during meiotic progression to metaphase II and concentrations decrease after fertilization (Ferrell et al., 1991; Dedieu et al., 1996).

In human oocytes, p42ERK2 is the main form of MAP kinase (Sun et al., 1999b). The activation pattern of MAP kinase in human oocytes is reminiscent of MAP kinase activity in other mammalian species such as pigs and mice. In humans, MAP kinase is inactive in immature oocytes, active in mature oocytes and the activity decreases after pronuclei formation after fertilization (Sun et al., 1999b). Therefore, although not widely studied in human oocytes, it appears that the MAP kinase pattern of activation in the cell cycle is similar to that of other mammalian species and, therefore, MAP kinase may serve a similar function during human oocyte maturation.

\section{Transcription and translation}

During the period of oocyte growth a large number of genes are transcribed and translated (Schultz, 1986). Protein translation actively continues during oocyte maturation and the accumulated transcripts and macromolecules are subsequently used for meiotic and early embryonic developmental events (Wickramasinghe and Albertini, 1993; 


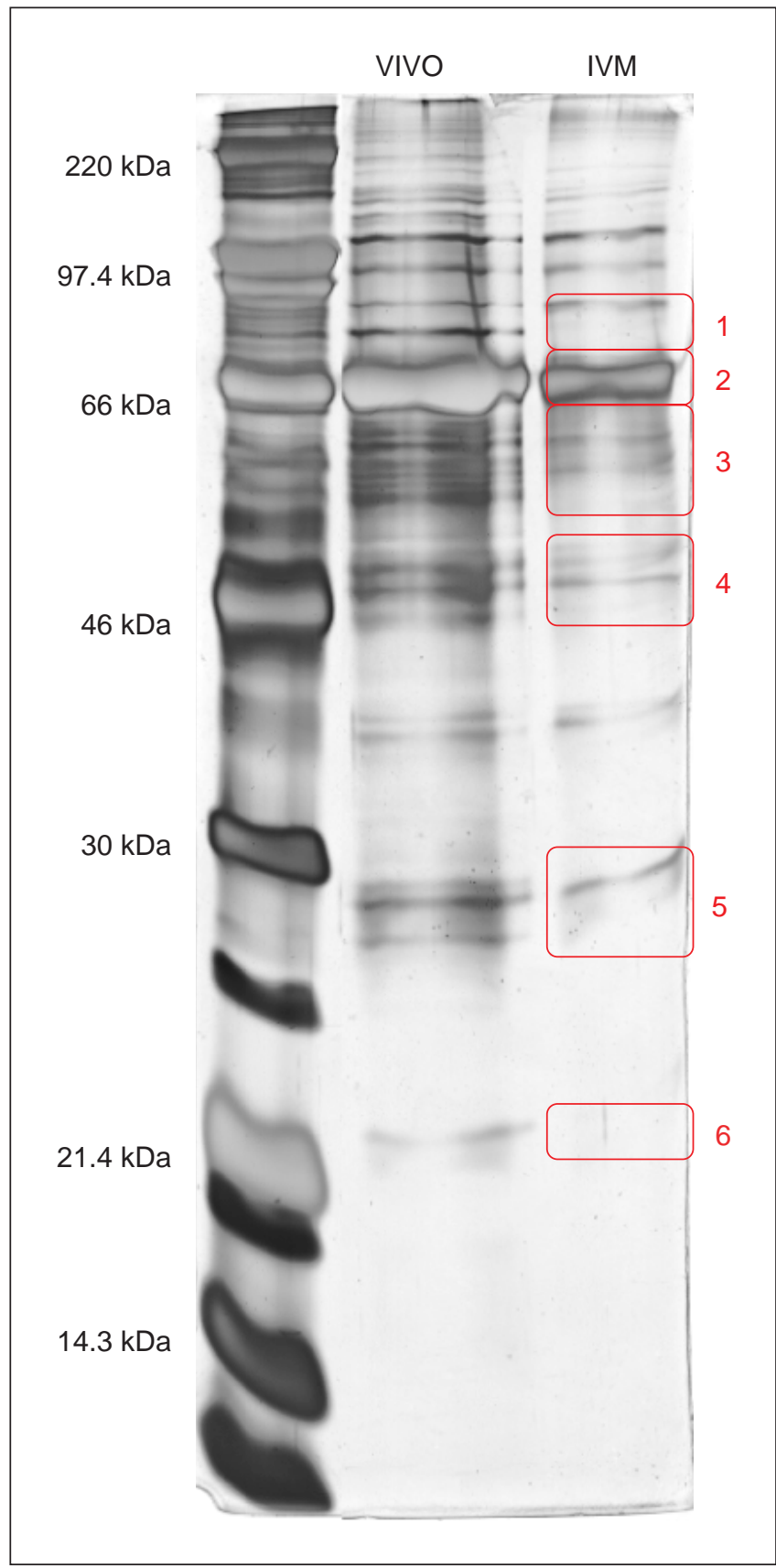

Fig. 8. One-dimensional $12 \%$ SDS-polyacrylamide gel of human oocyte proteins stained with silver nitrate. Each lane contains a single denuded in vitro matured (IVM) or in vivo matured (VIVO) human oocyte. Areas 1, 3, 4, 5 and 6 represent regions in which there appears to be an absence of particular proteins compared with the VIVO group.

Fair et al., 1995). Thus, it is commonly accepted that transcription and translation play an integral role in meiotic progression and subsequent embryo developmental competence.

Although it is clear that immature human oocytes retrieved from unstimulated ovaries can mature from the
GV stage to metaphase II in vitro, their subsequent embryonic development appears to be severely compromised (Trounson et al., 1994, 1996, 1998; Barnes et al., 1996; Moor et al., 1998). It has been suggested that the reduced developmental potential in human oocytes matured in vitro may be attributable to sub-optimal culture conditions, incomplete oocyte growth or abnormal cytoplasmic maturation (Moor et al., 1998).

Studies on protein content have revealed that in vitro matured metaphase II human oocytes, derived from ovaries of untreated women (IVM group), display a reduced protein content compared with in vivo matured metaphase II oocytes retrieved from ovaries of gonadotrophin treated patients (VIVO group). The one-dimensional protein profiles of single human metaphase II stage oocytes from the IVM and VIVO groups following silver staining are presented (Fig. 8). The human IVM oocytes have a reduced protein content compared with the VIVO group. Areas 1, $3,4,5$ and 6 represent regions in which there appears to be an absence of particular proteins. Isoelectric focusing and SDS-PAGE were used in combination to isolate and identify further variations in particular oocyte proteins. When the protein profiles of IVM and VIVO human oocytes were examined by two-dimensional SDS-PAGE there were nine specific human oocyte proteins expressed in the VIVO group that were not detected in the IVM group. A number of proteins cannot be detected in human oocytes matured in vitro and these are likely to include molecules essential for cell cycle regulation and normal embryo development. A reduction in oocyte protein content after in vitro maturation has also been reported in bovine oocytes (Kastrop et al., 1991). Whether these protein deficiencies are attributable to transcriptional inadequacies or translational defects is currently unknown.

Measurements of protein synthesis (Schultz et al., 1979; Salustri and Matrinozzi, 1983) reveal that oocytes cannot synthesize all the proteins they require during the growth phase (Schultz, 1986). Part of the protein content of the oocyte may be obtained from proteins taken up from serum (Glass, 1971). Alternatively, the follicular cells surrounding the oocyte could contribute to the protein content via a gap junction mediated transfer of molecules between the granulosa cells and the oocyte. Premature liberation of oocytes from small growing follicles may prevent the accumulation of follicular fluid proteins or cumulus cell transfer of proteins essential for developmental competence.

The available data indicate that in vitro matured human oocytes have a reduced protein content and the isolation and identification of the specific proteins that are either absent or at lower than required concentrations are needed.

\section{Control of progression of maturation in vitro and developmental competence}

Human oocytes appear to be unsynchronized in their response to maturational signals in vitro. This proposal is 
best demonstrated by the data reported by Trounson et al. (1994, 1998). A small proportion of oocytes (15-20\%) will extrude the first polar body by $24 \mathrm{~h}$ of culture, and by $43-47$ h, 60\% have matured to metaphase II. Similar data have been reported by Cha and Chian (1998) for oocytes obtained from untreated PCOS patients (Fig. 3). As discussed earlier, the factor responsible for the resumption of meiotic maturation is MPF and its associated p34 ${ }^{\text {cdc2 }}$ kinase activity is responsible for the cascade of events associated with meiotic maturation. The serine-threonine protein kinase inhibitor 6-dimethylaminopurine (DMAP) blocks GVBD and cell cycle progression in immature oocytes by inhibiting the post-translational dephosphorylation of p34cdc2 that triggers MPF activity (Jessus et al., 1991), but does not interfere with protein synthesis (Rime et al., 1989; Fulka et al., 1991).

Studies by Anderiesz et al. (2000b) have shown that DMAP in culture medium will reversibly block GVBD of mouse and human oocytes for 7 and $24 \mathrm{~h}$, respectively. Removal of DMAP and subsequent culture in medium without DMAP results in the same timing of formation of metaphase II oocytes as the untreated controls (Anderiesz et al., 2000b). It was hypothesized that DMAP treatment may synchronize nuclear maturational events in oocytes but there was no evidence of this effect in either mouse or human oocytes. DMAP treatment of human oocytes had no effect on fertilization or development to the blastocyst stage but decreased the developmental capacity of mouse embryos.

\section{Prospects for the future application of human oocyte maturation in vitro}

The recovery and maturation of oocytes from PCOS patients remains a very suitable alternative to surgery or diathermy of ovaries, for the establishment of pregnancy in these infertile women. It is apparent that large numbers of oocytes can be recovered by ultrasound-guided follicular aspiration and a reasonable pregnancy rate can be achieved when large numbers of unselected pronuclear or early cleavage stage embryos are transferred to the patients (Cha and Chian, 1998). The selection of the more developmentally competent embryos by extended culture (day 3 to day 6) and preimplantation genetic diagnosis to remove embryo aneuploidies would reduce the number of embryos transferred but still retain an acceptable pregnancy rate. Clearly, improvements can be made to the maturation conditions for retention of the potential developmental competence of immature oocytes and this aim should continue to be a priority for research on oocyte maturation. The benefits for PCOS patients is to avoid the need to administer fertility drugs to induce superovulation for mature oocyte collection and IVF. PCOS patients are susceptible to OHSS (Danninger and Feichtinger, 1997) and recovery of immature oocytes and their maturation in vitro remains a very attractive treatment strategy for pregnancy.
The recovery of immature oocytes from patients who have been treated with high doses of gonadotrophins for IVF and in whom administration of hCG has been purposefully withheld is attractive because LH and hCG are potent inducers of vascular endothelial growth factor (VEGF), which is closely related to the initiation and exacerbation of OHSS. Follicular aspiration and recovery of immature oocytes has already been successful in such a case (Jaroudi et al., 1997). This option could be adopted in clinical IVF to prevent the occurrence of OHSS.

It is also beneficial to recover oocytes from small nondominant follicles in natural ovulatory cycles, in patients that have had minimal ovarian stimulation with clomiphene citrate (Thornton et al., 1998; this review) or in PCOS patients with irregular menstrual cycles given progesterone for withdrawal bleeding, hCG at 10-14 days after progesterone and from which oocytes are recovered $36 \mathrm{~h}$ later (Chian et al., 1999a,b, 2000). Oocytes from these small follicles (down to $7 \mathrm{~mm}$ diameter) appear to be developmentally competent and may contribute to successful pregnancy and development to term. This will be a new application for in vitro maturation and is obviously clinically useful for IVF patients wishing to avoid treatment with large doses of $\mathrm{FSH}$, or for patients for whom superovulation treatment poses an unacceptable financial burden.

In the cases of recovering immature oocytes from follicles of patients at the normal time of ovulation, uterine receptivity for implantation and development will be similar to that for normal IVF patients or naturally cyclic women. The conditions required for uterine receptivity in anovulatory PCOS patients is not known and the use of progesterone for withdrawal bleeding may enhance implantation rates after embryo transfer.

\section{References}

Key references are identified by astersisks.

Adachi M, Yokoyama M and Tanioka $\mathbf{Y}$ (1982) Culture of marmoset ovarian oocytes in vitro. Japan Journal of Animal Reproduction $\mathbf{2 8}$ $51-55$

Agarwal ML, Agarwal A, Taylor WR and Stark GR (1995) p53 controls both the G2/M and the G1 cell cycle checkpoints and mediates reversible growth arrest in human fibroblasts Proceedings National Academy of Sciences USA 92 8493-8497

Almahbobi A and Trounson AO (1996) The role of intraovarian regulators in the aetiology of polycystic ovarian syndrome Reproductive Medicine Review 5 151-168

Almahbobi G, Anderiesz C, Hutchinson P, McFarlane JR, Wood C and Trounson AO (1996) Functional integrity of granulosa cells from the polycystic ovaries Clinical Endocrinology 44 571-580

Anderiesz C and Trounson AO (1995) The effect of testosterone on the maturation and developmental capacity of murine oocytes in vitro. Human Reproduction $102377-2381$

Anderiesz C, Ferraretti AP, Magli C, Fiorentino A, Fortini D, Gianaroli L, Jones GM and Trounson AO (2000a) Effect of recombinant human gonadotrophins on human, bovine and murine oocyte meiosis, fertilization and embryonic development in vitro. Human Reproduction 15 1140-1148

Anderiesz C, Fong C, Bongso A and Trounson AO (2000b) Regulation of human and mouse oocyte maturation in vitro with 6-diethylaminopurine Human Reproduction 15 379-388 
Araki K, Naito K, Haraguchi S, Suzuki R, Yokoyama M, Inoue M, Aizawa S, Toyoda Y and Sato E (1996) Meiotic abnormalities of c-mos knockout mouse oocytes: activation after first meiosis or entrance into third meiotic metaphase Biology of Reproduction 55 1315-1324

Bae IH and Foote RH (1975) Effects of hormones on the maturation of rabbit oocytes recovered from follicles of various sizes Journal of Reproduction and Fertility 432 357-360

Barnes FL (1999) In vitro maturation and developmental competence of human primary oocytes. In Handbook of In Vitro Fertilization 2nd Edn pp 85-97 Eds AO Trounson and DK Gardner. CRC Press, Boca Raton, FL

Barnes FL, Crombie A, Gardner DK, Kausche A, Lacham-Kaplan O, Suikkari A-M, Tiglias J, Wood C and Trounson AO (1995) Blastocyst development and birth after in vitro maturation of human primary oocytes, intracytoplasmic sperm injection and assisted hatching Human Reproduction 10 3243-3247

Barnes FL, Kausche A, Tiglias J, Wood C, Wilton L and Trounson A (1996) Production of embryos from in vitro-matured primary human oocytes Fertility and Sterility 65 1151-1156

Basu J, Logarinho E, Herrmann S, Bousbaa H, Chan GK, Yen TJ, Sunke CE and Goldberg ML (1998) Localization of the Drosophila checkpoint control protein Bub3 to the kinetochore requires Bub1 but not Zw10 or Rod Chromosoma 107 376-385

Basu J, Bousbaa H, Logarinho E, Li Z, Williams BC, Lopes C, Sunkel CE and Goldberg ML (1999) Mutations in the essential spindle checkpoint gene Bub1 cause chromosome missegregation and fail to block apoptosis in Drosophila. Journal of Cell Biology 146 13-28

Bevers MM, Dieleman SJ, van den Hurk R and Izadyar F (1997) Regulation and modulation of oocyte maturation in the bovine Theriogenology 47 13-22

Blondin P and Sirard M-A (1995) Oocyte and follicular morphology as determining characteristics for developmental competence in bovine oocytes Molecular Reproduction and Development 41 54-62

Bluyssen HA, Naus NC, van Os RI, Jaspers I, Hoeijmakers JH and de Klein A (1999) Human and mouse homologs of the Schizosaccharomyces pombe rad17+ cell cycle checkpoint control gene Genomics 55 219-228

Bousquet D, Twagiramungu H, Morin N, Brisson C, Carboneau G and Durocher J (1999) In vitro embryo production in the cow: an effective alternative to the conventional embryo production approach Theriogenology 51 59-70

Canipari R, Palombi FR and Mangia F (1984) Early programming of maturation competence in mouse oogenesis Developmental Biology 102 $519-524$

Casenghi M, Mangiacasale R, Tuynder M, Caillet-Fauquet P, Elhajouji A Lavia P, Mousset S, Kirsch-Volders M and Cundari E (1999) p53independent apoptosis and p53-dependent block of DNA replication following mitotic spindle inhibition in human cells Experimental Cell Research 250 339-350

Cha K-Y and Chian R-C (1998) Maturation in vitro of immature human oocytes for clinical use Human Reproduction Update 4 103-120

Cha KY, Koo JJ, Ko JJ, Choi DH, Han SY and Yoon TK (1991) Pregnancy after in vitro fertilization of human follicular oocytes collected from nonstimulated cycles, their culture in vitro and their transfer in a donor oocyte program Fertility and Sterility 55 109-113

*Chian RC, Buckett WM, Too L-L and Tan S-L (1999a) Pregnancies resulting from in vitro matured oocytes retrieved from patients with polycystic ovary syndrome after priming with human chorionic gonadotropin Fertility and Sterility 72 639-642

Chian RC, Gülekli B, Buckett WM and Tan S-L (1999b) Priming with human chorionic gonadotropin before retrieval of immature oocytes in women with infertility due to the polycystic ovary syndrome New England Journal of Medicine 341 1624-1626

Chian RC, Buckett WM, Tulandi T and Tan SL (2000) Prospective randomized study of human chorionic gonadotrophin priming before immature oocyte retrieval from unstimulated women with polycystic ovarian syndrome Human Reproduction 15 165-170

Clarke PR and Karsenti E (1991) Regulation of p34cdc2 protein kinase: new insights into protein phosphorylation and the cell cycle Journal of Cell Science 100 509-514
Cobo AC, Requena A, Neuspiller F, Aragonis M, Mercader A, Navarro J, Simon C, Remohi J and Pellicer A (1999) Maturation in vitro of human oocytes from unstimulated cycles: selection of the optimal day for ovum retrieval based on follicular size Human Reproduction 14 1864-1868

Coskun S, Jaroudi KA, Hollanders JMG, Atared AM and Roca GL (1998) Recovery and maturation of immature oocytes in patients at risk for ovarian hyperstimulation syndrome Journal of Assisted Reproduction and Genetics 15 372-377

Cross DA and Smythe C (1998) PD 98059 prevents establishment of the spindle assembly checkpoint and inhibits the G2-M transition in meiotic but not mitotic cell cycles in Xenopus. Experimental Cell Research 241 $12-22$

Cross SM, Sanchez CA, Morgan CA, Schimke MK, Ramel S, Idzerda RL, Raskind WH and Reid BJ (1995) A p53-dependent mouse spindle checkpoint Science $\mathbf{2 6 7}$ 1353-1356

Crozet N, Ahmed-Ali M and Dubos MP (1995) Developmental competence of goat oocytes from follicles of different size categories following maturation, fertilization and culture in vitro. Journal of Reproduction and Fertility 103 293-298

Dandekar PV, Martin MC and Glass RH (1991) Maturation of immature oocytes by coculture with granulosa cells Fertility and Sterility 55 95-99

Danninger B and Feichtinger W (1997) Ovarian hyperstimulation syndrome (OHSS): alternative stimulation regime for high risk patients. In Ovarian Hyperstimulation Syndrome pp 53-57 Eds AP Ferraretti, L Gianaroli and BC Tarlatzis. Serono Symposia, Rome

Dedieu T, Gall L, Crozet N, Sevellec C and Ruffini S (1996) Mitogenactivated protein kinase activty during goat oocyte maturation and the acquisition of meiotic competence Molecular Reproduction and Development 45 351-358

De Vos A, Van de Velde H, Joris H and Van Steirteghem A (1999) In vitro matured metaphase-I oocytes have a lower fertilization rate but similar embryo quality as mature metaphase-II oocytes after intracytoplasmic sperm injection Human Reproduction 14 1859-1863

Di Leonardo A, Khan SH, Linke SP, Greco V, Seidita G and Wahl GM (1997) DNA replication in the presence of mitotic spindle inhibitors in human and mouse fibroblasts lacking either p53 or pRb function Cancer Research 57 1013-1019

Doree M, Labbe JC and Picard A (1989) M phase promoting factor: its identification as the $M$ phase specific histone $\mathrm{H} 1$ kinase and its activation by phosphorylation Journal of Cell Science (Supplement) 12 $39-51$

Dubey AK, Wang HA, Duffy P and Penzias AS (1995) The correlation between follicular measurements, oocyte morphology and fertilization rates in an in vitro fertilization program Fertility and Sterility 64 787-790

Dunphy WG and Newport JW (1989) Fission yeast p13 blocks mitotic activation and tyrosine dephosphorylation of the Xenopus cdc2 protein kinase Cell 58 181-191

Durinzi KL, Saniga EM and Lanzendorf SE (1995) The relationship between size and maturation in vitro in the unstimulated human oocyte Fertility and Sterility $\mathbf{6 3}$ 404-406

Durinzi KL, Wentz AC, Saniga EM, Johnson DE and Lanzendorf SE (1997) Follicle stimulating hormone effects on immature human oocytes: in vitro maturation and hormone production Journal of Assisted Reproduction and Genetics 14 199-204

Edirisinghe WR, Junk SM, Matson PL and Yovich JL (1997) Birth from cryopreserved embryos following in vitro maturation of oocytes and intracytoplasmic sperm injection Human Reproduction 12 1056-1058

Edwards RG (1965) Maturation in vitro of mouse, sheep, cow, pig, rhesus monkey and human ovarian oocytes Nature (London) 208 349-351

Eldar-Geva T, Calderon I, MacLachlan V and Healy D (1999) Endocrinology of IVF. In Handbook of In Vitro Fertilization 2nd Edn pp 35-66 Eds AO Trounson and DK Gardner. CRC Press, Boca Raton, FL

Eppig JJ and Schroeder AC (1989) Capacity of mouse oocytes from preantral follicles to undergo embryogenesis and development to live young after growth, maturation and fertilization in vitro. Biology of Reproduction 41 268-276 
Eppig JJ, Wigglesworth K and O'Brien MJ (1992) Developmental capacity of mouse oocytes matured in vitro: effects of gonadotropic stimulation, follicular origin and oocyte size Journal of Reproduction and Fertility 95 119-127

Fair T, Hyttel P and Greve T (1995) Bovine oocyte diameter in relation to maturational competence and transcriptional activity Molecular Reproduction and Development 42 437-442

Farhi J, Nahum H, Zakut H and Levran D (1997) Incubation with sperm enhances in vitro maturation of the oocyte from the germinal vesicle to the M2 stage Fertility and Sterility 68 318-322

Fauser B and van Heusden A (1997) Manipulation of human ovarian function: physiological concepts and clinical consequences Endocrinology Review 1 71-103

Felix MA, Labbe JC, Doree M, Hunt T and Karsenti E (1990) Triggering of cyclin degradation in interphase extracts of amphibian eggs by cdc2 kinase Nature 346 379-382

Ferrell JE, Wu M, Gerhart JC and Martin GS (1991) Cell cycle tyrosine phosphorylation of p34cdc2 and MAP-kinase homolog in Xenopus oocytes and eggs Molecular and Cellular Biology 11 1965-1971

Fissore RA, He CL and Vande Woude GF (1996) Potential role of mitogenactivated protein kinase during meiosis resumption in bovine oocytes Biology of Reproduction 55 1261-1270

Fogarty P, Campbell SD, Abu-Shumays R, Phalle BS, Yu KR, Uy GL, Goldberg ML and Sullivan W (1997) The Drosophila grapes gene is related to checkpoint gene $\operatorname{chk} 1 / \mathrm{rad} 27$ and is required for late syncytial division fidelity Current Biology 7 418-426

Frankel AE and Fischinger PJ (1976) Nucleotide sequence in mouse DNA and RNA specific for Moloney sarcoma virus Proceedings National Academy of Sciences USA 73 3705-3709

Freire R, Murguia JR, Tarsounas M, Lowndes NF, Moens PB and Jackson SP (1998) Human and mouse homologs of Schizosaccharomyces pombe $\operatorname{rad} 1(+)$ and Saccharomyces cerevisiae RAD17: linkage to checkpoint control and mammalian meiosis Genes and Development 12 2560-2573

Fulka A, Jr, Leibfried-Rutledge ML and First NL (1991) Effect of 6-dimethylaminopurine on germinal vesicle breakdown of bovine oocytes Molecular Reproduction and Development 29 379-384

Fulka J, Jr, Bradshaw J and Moor R (1994) Meiotic cycle checkpoints in mammalian oocytes Zygote 2 351-354

Fulka J, Jr, Moor RM and Fulka J (1995a) Replicating DNA does not block germinal vesicle breakdown in mouse oocytes Journal of Experimental Zoology 272 245-248

Fulka J, Jr, Moor RM and Fulka J (1995b) Mouse oocyte maturation: meiotic checkpoints Experimental Cell Research 219 414-419

Fulka J, Jr, Kalab P, First NL and Moor RM (1997) Damaged chromatin does not prevent the exit from metaphase I in fused mouse oocytes Human Reproduction 12 2473-2476

Gautier J, Norbury C, Lohka M, Nurse P and Maller JL (1988) Purified maturation-promoting factor contains the product of a Xenopus homolog of the fission yeast cell cycle control gene cdc2+Cell $\mathbf{5 4}$ 433-439

Gautier J, Minshull J, Lohka M, Glotzer M, Hunt T and Maller JL (1990) Cyclin is a component of maturation-promoting factor from Xenopus. Cell 60 487-494

Gautier J, Solomon MJ, Booher RN, Bazan JF and Kirschner MW (1991) cdc25 is a specific tyrosine phosphatase that directly activates p34cdc2 Cell 67 197-211

Gilchrist RB, Nayudu PL, Nowshari MA and Hodges JK (1995) Meiotic competence of marmoset monkey oocytes is related to follicle size and oocyte-somatic cell associations Biology of Reproduction 52 1234-1243

Glass LE (1971) Transmission of maternal proteins into oocytes Advances in Biosciences 6 29-58

Glotzer M, Murray A and Kirschner M (1991) Cyclin is degraded by the ubiquitin pathway Nature 349 132-138

Gomez E, Tarin JJ and Pellicer A (1993) Oocyte maturation in humans: the role of gonadotrophins and growth factors Fertility and Sterility 60 40-46

Gosden RG and Bownes M (1995) Cellular and molecular aspects of oocyte development. In Gametes - Oocytes Cambridge Reviews in
Human Reproduction, pp 23-55 Eds JG Grudzinskas and JL Yovich. Cambridge University Press, Cambridge

Goud PT, Goud AP, Qian C, Laverge H, Van der Elst J, De Sutter P and Dhont M (1998) In vitro maturation of human germinal vesicle stage oocytes: role of cumulus cells and epidermal growth factor in the culture medium Human Reproduction 13 1638-1644

Goudet G, Bezard J, Duchamp G, Gerard N and Palmer E (1997) Equine oocyte competence for nuclear and cytoplasmic in vitro maturation: effect of follicle size and hormonal environment Biology of Reproduction 57 232-245

Gougeon A (1996) Regulation of ovarian follicular development in primates: facts and hypotheses Endocrinology Review 17 121-155

Gougeon A and Lefevre B (1983) Evolution of the diameters of the largest healthy and atretic follicles during the human menstrual cycle Journal of Reproduction and Fertility 69 497-502

Greenwald GS and Terranova PF (1988) Follicular selection and its control. In The Physiology of Reproduction pp 387-445 Eds E Knobil, JD Neill, CL Markert, SG Greenwals and DW Pfaff. Raven Press, New York

Haccard O, Jessus C, Cagla X, Goris J, Meleveed W and Ozon R (1990) In vivo activation of microtubule-associated protein kinase during meiotic maturation in the Xenopus oocyte European Journal of Biochemistry 192 633-642

Haccard O, Lewellyn A, Hartley RS, Erikson E and Maller JL (1995) Induction of Xenopus oocyte meiotic maturation by MAP kinase Developmental Biology 168 677-682

Haines CJ and Emes AL (1991) The relationship between follicle diameter, fertilization rate and microscopic embryo quality Fertility and Sterility 55 205-207

Hartwell LH and Weinert TA (1989) Checkpoints: controls that ensure the order of cell cycle events Science 246 629-634

Heikinheimo O, Lanzendorf SE, Baka SG and Gibbons WE (1995) Cell cycle genes c-mos and cyclin-B1 are exposed in a specific pattern in human oocytes and preimplantation embryos Human Reproduction 10 699-707

*Heikinheimo O, Toner JP, Lanzendorf SE, Billeter M, Veeck LL and Gibbons WE (1996) Messenger ribonucleic acid kinetics in human oocytes - effects of in vitro culture and nuclear maturational status Fertility and Sterility 65 1003-1008

Hershko A, Ganoth D, Sudakin V, Dahan A, Cohen LH, Luca FC, Ruderman JV and Eytan E (1994) Components of a system that ligates cyclin to ubiquitin and their regulation by the protein kinase cdc2 Journal of Biological Chemistry 269 4940-4946

Hwu Y-M, Lee RK-K, Chen C-P, Su J-T, Chen Y-W and Lin S-P (1998) Development of hatching blastocysts from immature human oocytes following in vitro maturation and fertilization using a co-culture system Human Reproduction 13 1916-1921

Inoue M, Naito K, Aoki F, Toyoda Y and Sato E (1995) Activation of mitogen-activated protein kinase during meiotic maturation in porcine oocytes Zygote 3 265-271

Jablonski SA, Chan GK, Cooke CA, Earnshaw WC and Yen TJ (1998) The hBUB1 and hBUBR1 kinases sequentially assemble onto kinetochores during prophase with hBUBR1 concentrating at the kinetochore plates in mitosis Chromosoma 107 386-396

Janssenwillen C, Nagy ZP and Van Steirteghem A (1995) Maturation of human cumulus-free germinal vesicle-stage oocytes to metaphase II by co-culture with monolayer Vero cells Human Reproduction 10 375-378

Jaroudi KA, Hollanders JMG, Sieck UV, Roca GL, El-Nour AM and Coskun S (1997) Pregnancy after transfer of embryos which were generated from in vitro matured oocytes Human Reproduction 12 857-859

*Jaroudi KA, Hollanders JMG, Elnour AM, Roca GL, Atared AM and Coskun S (1999) Embryo development and pregnancies from in vitro matured and fertilized human oocytes Human Reproduction 14 1749-1751

Jessus C, Rime H, Haccard O et al. (1991) Tyrosine phosphorylation of p34cdc2 and p42 during meiotic maturation of Xenopus oocyte Development 111 813-820

Jones GM, Trounson AO, Gardner DK, Kausche A, Lolatgis N and Wood 
C (1998) Evolution of a culture protocol for successful blastocyst development and pregnancy Human Reproduction 13 169-177

Kastrop PMM, Bevers MM, Destree OHJ and Kruip TAM (1991) Protein synthesis and phosphorylation patterns of bovine oocytes maturing in vivo. Molecular Reproduction and Development 29 271-275

Kawahara H and Yokosawa H (1994) Intracellular calcium mobilization regulated the activity of $26 \mathrm{~S}$ proteasome during the metaphaseanaphase transition in the ascidian meiotic cycle Developmental Biology 166 623-633

Kosako H, Gotoh Y and Nishida E (1994) Mitogen-activated protein kinase kinase is required for the mos-induced metaphase arrest Journal of Biological Chemistry 26928 354-28 358

Labbe JC, Capony JP, Caput D, Cavadore JC, Derancourt J, Kaghad M, Lelias JM, Picard A and Doree M (1989) MPF from starfish oocytes at first meiotic metaphase is a heterodimer containing one molecule of cdc2 and one molecule of cyclin B EMBO Journal 8 3053-3058

Lanni JS and Jacks T (1998) Characterization of the p53-dependent postmitotic checkpoint following spindle disruption Molecular and Cellular Biology 18 1055-1064

Lefevre B, Gougeon A and Testart J (1987) In vitro oocyte maturation: some questions concerning the initiation and prevention of this process in humans Human Reproduction 2 495-497

LeMarie-Adkins R, Radke K and Hunt PA (1997) Lack of checkpoint control at the metaphase/anaphase transition: a mechanism of meiotic nondisjunction in mammalian females Journal of Cell Biology 139 1611-1619

Li Y and Benezra R (1996) Identification of a human mitotic checkpoint gene:hsMAD2 Science 274 246-248

Lieberman HB, Hopkins KM, Nass M, Demetricks D and Davey S (1996) A human homolog of the Schizosaccharomyces pombe rad9+ checkpoint control gene Proceedings National Academy of Sciences USA 93 13 890-13 895

Liu J, Katz E, Garcia JE, Compton G and Baramki TA (1997) Successful in vitro maturation of human oocytes not exposed to human chorionic gonadotropin during ovulation induction, resulting in pregnancy Fertility and Sterility 67 566-568

Lonergan P, Monaghan P, Rizos D, Boland MP and Gordon I (1994) Effect of follicle size on bovine oocyte quality and developmental competence following maturation, fertilization, and culture in vitro. Molecular Reproduction and Development 37 48-53

McCaffrey C, Lu KH and Sreenan JM (1992) Factors involved in the in vitro development of IVF cattle ova Proceedings of the Irish Grassland and Animal Production Association 18th Annual Research Meeting, Dublin, pp 33-34

McNatty KP, Hillier SG, Van den Boogaard AMJ et al. (1983) Follicular development during the luteal phase of the human menstrual cycle Journal of Clinical Endocrinology and Metabolism 56 1022-1031

Marathi UK, Dahlen M, Sunnerhagen P, Romero AV, Ramagli LS, Siciliano MJ, Li L and Legerski RJ (1998) RAD1, a human structural homolog of the Schizosaccharomyces pombe RAD1 cell cycle checkpoint gene Genomics 54 344-347

Martino A, Magos T, Palomo MJ and Paramio MT (1994) Meiotic competence of prepubertal goat oocytes Theriogenology 41 969-980

Masui Y and Markert CL (1971) Cytoplasmic control of nuclear behaviour during meiotic maturation of frog oocytes Journal of Experimental Zoology 177 129-146

Mikkelsen AL, Smith SD and Lindenberg S (1999) In vitro maturation of human oocytes from regularly menstruating women may be successful without follicle stimulating hormone priming Human Reproduction $\mathbf{1 4}$ 1847-1851

Moor RM and Trounson AO (1977) Hormonal and follicular factors affecting maturation of sheep oocytes in vitro and their subsequent developmental capacity Journal of Reproduction and Fertility 49 101-109

*Moor RM, Dai Y, Lee C and Fulka J, Jr (1998) Oocyte maturation and embryonic failure Human Reproduction Update 4 223-236

Motlik J and Fulka J (1986) Factors affecting meiotic competence of pig oocytes Theriogenology 25 87-96

Murray AW, Solomon MJ and Kirschner MW (1989) The role of cyclin synthesis and degradation in the control of MPF activity Nature 339 280-286

Nagy ZP, Janssenwillen C, Liu J, Loccufier A, Devroey $P$ and Van Steirteghem A (1996) Pregnancy and birth after intracytoplasmic sperm injection of in vitro matured germinal-vesicle stage oocytes: case report Fertility and Sterility 65 1047-1050

Nebreda AR and Hunt T (1993) The c-mos proto-oncogene protein kinase turns on and maintains the activity of MAP kinase, but not MPF, in cellfree extracts of Xenopus oocytes and eggs EMBO Journal 12 1979-1986

O'Keefe SJ, Wolfes H, Kiessling AA and Cooper GM (1989) Microinjection of antisence c-mos oligonucleotide prevents meiosis II in the maturing mouse egg Proceedings National Academy of Sciences USA 86 7038-7042

O'Keefe SJ, Kiessling AA and Cooper GM (1991) The c-mos gene product is required for cyclin $\mathrm{B}$ accumulation during meiosis of mouse eggs Proceedings National Academy of Sciences USA 88 7869-7872

Osborn J (1993) Oocyte retrieval and maturation. In Handbook of In Vitro Fertilization pp 17-32 Eds A Trounson and DK Gardner. CRC Press, Boca Raton, FL

Otoi T, Yamamoto K, Koyama N, Tachikawa S and Suzuki T (1997) Bovine oocyte diameter in relation to developmental competence Theriogenology 48 769-774

Ouyang B, Lan Z, Meadows J, Pan H, Fukasawa K, Li W and Dai W (1998) Human Bub1: a putative spindle checkpoint kinase closely linked to cell proliferation Cell Growth and Differentiation 9 877-885

Pal SK, Torry D, Serta R, Crowell RC, Seibel MM, Cooper GM and Kiessling AA (1994) Expression and potential function of the c-mos protoncogene in human eggs Fertility and Sterility 61 496-503

Parker AE, Van de Weyer I, Laus MC, Verhasselt P and Luyten WHML (1998a) Identification of a human homologue of the Schizosaccharomyces pombe rad17+ checkpoint gene Journal of Biological Chemistry 27318 340-18 346

Parker AE, Van de Weyer I, Laus MC, Oostveen I, Yon J, Verhasselt P and Luyten WHML (1998b) A human homologue of the Schizosaccharomyces pombe rad1+ checkpoint gene encodes an exonuclease Journal of Biological Chemistry 27318 332-18 339

Parker LL, Atherton-Fessler S, Lee MS, Ogg S, Falk JL, Swenson KI and Piwnica-Worms H (1991) Cyclin promotes the tyrosine phosphorylation of p34cdc2 in a wee1+ dependent manner EMBO Journal 10 1255-1263

Pavlok A, Lucas-Hahn A and Niemann H (1992) Fertilization and developmental competence of bovine oocytes derived from different categories of antral follicles Molecular Reproduction and Development 31 63-67

Pincus G and Enzmann EV (1935) The comparative behavior of mammalian eggs in vivo and in vitro. The activation of ovarian eggs Journal of Experimental Medicine $\mathbf{6 2} 655$

Pines J and Hunter RH (1989) Isolation of human cyclin cDNA: evidence for cyclin mRNA and protein regulation in the cell cycle and for interaction with p34 ${ }^{\text {cdc2 }}$ Cell 58 833-846

Prins GS, Wagner C, Weidel L, Gianfortoni J, Marut EL and Scommegna A (1987) Gonadotrophins augment maturation and fertilization of human immature oocytes cultured in vitro. Fertility and Sterility 61 891-894

Rime H, Neant I, Guerrier P and Ozon R (1989) 6-Dimethylaminopurine (6-DMAP), a reversible inhibitor of the transition to metaphase during the first meiotic division of the mouse oocyte Developmental Biology 133 169-179

Roy LM, Singh B, Gautier J, Arlinghaus R, Nordeen S and Maller JL (1990) The cyclin component B2 is a substrate for the $c-m o s{ }^{x e}$ protooncogene product Cell 61 825-831

Roy LM, Haccard O, Izumi T, Lattes BG, Lewellyn AL and Maller JL (1996) Mos proto-oncogene function during oocyte maturation in Xenopus. Oncogene 12 2203-2211

Russell JB (1998) Immature oocyte retrieval combined with in vitro oocyte maturation Human Reproduction 13 63-70

Russell JB, Knezevich KM, Fabian KF and Dickson JA (1997) Unstimulated immature oocyte retrieval: early versus midfollicular endometrial priming Fertility and Sterility $\mathbf{6 7} 616-620$

Russell P and Nurse P (1986) cdc25+ functions as an inducer in the mitotic control of fission yeast Cell 45 145-153 
Sagata N, Oskarsson M, Copeland T, Brumbaugh J and Vande Woude GF (1988) Function of c-mos proto-oncogene product in meiotic maturation in Xenopus oocytes Nature 335 519-525

Salha O, Nugent D, Dada T, Kaufmann S, Levett S, Jenner L, Lue S and Sharma V (1998a) The relationship between follicular fluid aspirate volume and oocyte maturity in in vitro fertilization cycles Human Reproduction 13 1901-1906

Salha O, Abusheika N and Sharma V (1998b) Dynamics of human follicular growth and in vitro oocyte maturation Human Reproduction Update $\mathbf{4}$ 816-832

Salustri A and Martinozzi M (1983) A comparison of protein synthesis activity in in vitro cultured denuded and follcile-enclosed oocytes Cell Biology International Reports 7 1049-1055

Sato E, Iritani A and Nishikawa Y (1977) Factors involved in maturation of pig and cattle follicular oocytes cultured in vitro. Japan Journal of Animal Reproduction 28 12-18

Schramm RD, Tennier MT, Boatman DE and Bavister BD (1993) Chromatin configurations and meiotic competence of oocytes are related to follicular diameter in nonstimulated rhesus monkeys Biology of Reproduction 48 349-356

Schultz RM (1986) Molecular aspects of mammalian oocyte growth and maturation. In Experimental Approaches to Mammalian Embryonic Development pp 195-237 Eds J Rossant and RA Pederson. Cambridge University Press, Cambridge

Schultz RM, Letourneau GE and Wassarman PM (1979) Program of early development in the mammal: changes in the patterns and absolute rates of tubulin and total protein synthesis during oocytes growth in the mouse Developmental Biology 73 120-133

Scott RT, Hofman GE, Muasher SJ, Acosta AA, Kreiner DK and Rosenwaks Z (1989) Correlation of follicular diameter with oocyte recovery and maturity at the time of transvaginal follicular aspiration Journal of In Vitro Fertilization and Embryo Transfer 6 73-75

Simonetti S, Veeck LL and Jones HW, Jr (1985) Correlation of follicular fluid volume with oocyte morphology from follicles stimulated by human menopausal gonadotropin Fertility and Sterility 44 177-180

Sorensen RA and Wassarman PM (1976) Relationship between oocyte growth and meiotic maturation of the mouse oocyte Developmental Biology 50 531-536

Staigmiller RB and Moor RM (1984) Effect of follicle cells on the maturation and developmental competence of ovine oocytes matured outside the follicle Gamete Research 9 221-229

Sun QY, Rubinstein S and Breitbart H (1999a) Map kinase activity is downregulated by phorbol ester during mouse oocyte maturation and egg activation in vitro. Molecular Reproduction and Development 52 310-318

Sun QY, Blumenfeld Z, Rubinstein S, Goldman S, Gonen Y and Breitbart H (1999b) Mitogen-activated protein kinase in human eggs Zygote 7 181-185

Tan SJ and Lu KH (1990) Effects of different oestrous stages of ovaries and sizes of follicles on generation of bovine embryos in vitro. Theriogenology 33335 (Abstract)

Taylor SS and McKeon F (1997) Kinetochore localization of murine Bub1 is required for normal mitotic timing and checkpoint response to spindle damage Cell 89 727-735

Thibault C, Gerard M and Menezo Y (1975) Preovulatory and ovulatory mechanisms in oocyte maturation Journal of Reproduction and Fertility 45 605-610

Thornton MH, Francis MM and Paulson RJ (1998) Immature oocyte retrieval: lessons from unstimulated IVF cycles Fertility and Sterility $\mathbf{7 0}$ 647-650

Toth TL, Baka SG, Veeck LL, Jones HW, Jr, Muasher S and Lanzendorf SE (1994) Fertilization and in vitro development of cryopreserved human prophase I oocytes Fertility and Sterility 61 891-894

*Trounson A, Wood C and Kausche A (1994) In vitro maturation and the fertilization and developmental competence of oocytes recovered from untreated polycystic ovarian patients Fertility and Sterility 62 353-362

Trounson A, Bongso A, Szell A and Barnes FL (1996) Maturation of human and bovine primary oocytes in vitro for fertilization and embryo production Singapore Journal of Obstetrics and Gynaecology 27 78-84

Trounson AO, Anderiesz C, Jones GM, Kausche A, Lolatgis N and Wood C (1998) Oocyte maturation Human Reproduction 13 52-62

Tsafiri A and Channing CP (1975) Influence of follicular maturation and culture conditions on the meiosis of pig oocytes in vitro. Journal of Reproduction and Fertility 43 149-152

Tsuji K, Sowa M and Nakano R (1985) Relationship between human oocyte maturation and different follicular sizes Biology of Reproduction 32 413-417

Tucker MJ, Wright G, Morton PC and Massey JB (1998) Birth after cryopreservation of immature oocytes with subsequent in vitro maturation Fertility and Sterility 70 578-579

Van Blerkom J and Davis PW (1998) DNA strand breaks and phosphatidylserine redistribution in newly ovulated and cultured mouse and human oocytes: occurrence and relationship to apoptosis Human Reproduction 13 1317-1324

Veeck LL, Wortham JW, Jr, Witmyer J, Sandow BA, Acosta AA, Garcia JE, Jones GS and Jones HW, Jr (1983) Maturation and fertilization of morphologically immature human oocytes in a program of in vitro fertilization Fertility and Sterility 39 594-602

Verlhac MH, de Pennart H, Maro B, Cobb MH and Clarke HJ (1993) MAP kinase becomes stably activated at metaphase and is associated with microtubule-organizing centers during meiotic maturation of mouse oocytes Developmental Biology 158 330-340

Verlhac MH, Kubiak JZ, Clarke HJ and Maro B (1994) Microtubule and chromatin behaviour following MAP kinase activity but not MPF activity during meiosis in mouse oocytes Development 120 1017-1025

Verlhac MH, Kubiak JZ, Weber M, Geraud G, Colledge WH, Evans MJ and Maro B (1996) Mos is required for MAP kinase activation and is involved in microtubule organization during meiotic maturation in the mouse Development 122 815-822

Volkmer E and Karnitz LM (1999) Human homologs of Schizosaccharomyces pombe rad1, hus1 and rad9 form a DNA damageresponsive protein complex Journal of Biological Chemistry $\mathbf{2 7 4}$ 567-570

Weiss RS, Kostrub CF, Enoch T and Leder P (1999) Mouse Hus1, a homolog of the Schizosaccharomyces pombe hus $1+$ cell cycle checkpoint gene Genomics 59 32-39

Whitacre KS, Seifer DB, Friedman Cl, Coskun S, Kennard KA, Kim MH and Alak BM (1998) Effects of ovarian source, patient age and menstrual cycle phase on in vitro maturation of immature human oocytes Fertility and Sterility 70 1015-1021

Whitaker M (1996) Control of meiotic arrest Reviews of Reproduction 1 127-135

Wickramasinghe D and Albertini DF (1993) Cell cycle control during mammalian oogenesis. In Current Topics in Developmental Biology pp 125-153 Ed. RA Pederson. Academic Press, San Diego

Wittmaack FM, Kreger DO, Blasco L, Tureck RW, Mastroianni L, Jr and Lessey BA (1994) Effect of follicular size on oocyte retrieval, fertilization, cleavage and embryo quality in in vitro fertilization cycles: a 6-year data collection Fertility and Sterility 62 1205-1210

Wynn P, Picton HM, Krapez JA, Rutherford AJ, Balen AH and Gosden RG (1998) Pretreatment with follicle stimulating hormone promotes the numbers of human oocytes reaching metaphase II by in vitro maturation Human Reproduction 13 3132-3138

Xu W, Ladner KJ and Smith LD (1992) Evidence that Mos protein may not act directly on cyclin Proceedings National Academy of Sciences USA 89 4573-4577

Zhao X, Singh B and Batten BE (1991) The role of c-mos proto-oncoprotein in mammalian meiotic maturation Oncogene 6 43-49 